\title{
On the Effects of Ranking by Unemployment Duration *
}

\author{
Javier Fernández-Blanco ${ }^{\dagger} \quad$ Edgar Preugschat ${ }^{\ddagger}$
}

February 20, 2018

\begin{abstract}
We propose a theory based on the firm's hiring behavior that rationalizes the observed significant decline of callback rates for an interview and exit rates from unemployment and the mild decline of reemployment wages over unemployment duration. We build a directed search model with symmetric incomplete information on worker types and non-sequential search by firms. Sorting due to firms' testing of applicants in the past makes expected productivity fall with duration, which induces firms to rank applicants by duration. In equilibrium callback and exit rates both fall with unemployment duration. In our numerical exercise using U.S. data we show that our model can replicate quite well the observed falling patterns, with the firm's ranking decision accounting for a sizable part.
\end{abstract}

JEL classification: D 82; D83; J64

Keywords: Ranking; Sorting; Directed Search; Exit Rates; Wages; Unemployment Duration

*We would like to thank Manuel Arellano, Irma Clots, Francisco González, Philip Jung, Leo Kaas, Philipp Kircher, Joan Llull, Espen R. Moen, Ricardo Mora, Iliana Reggio, Robert Shimer, Antonella Trigari, Ludo Visschers, and participants at numerous seminars and conferences for their comments and suggestions. Fernández-Blanco gratefully acknowledges financial support from the Spanish Ministry of Science and Technology under Grant Nos. ECO 2010-19357 and ECO 2013-46395, and from the Ministry of Economy and Competitiveness through the Severo Ochoa Programme for Centres of Excellence in R\&D (SEV-2015-0563). Edgar Preugschat thanks the German Research Foundation for support through Priority Programme SPP 1764.

${ }^{\dagger}$ Department of Economics UAB, Barcelona GSE and MOVE (email: javier.fernandez@uab.cat)

${ }_{\ddagger}^{\ddagger}$ Department of Economics, Technical University of Dortmund and Ruhr Graduate School (email: e.preugschat@gmail.com) 


\section{Introduction}

It is well documented that exit rates from unemployment strongly fall with unemployment duration. Most explanations of this pattern have focused on the supply side, assigning a very limited role to firms. A primary reason for this has been the scarcity of empirical evidence about the hiring process. However, recent field experiments provide strong indication that firms make use of the information that unemployment duration conveys for their recruiting decisions. By submitting applications of fictitious workers to job postings, Oberholzer-Gee (2008), Kroft et al. (2013) and Eriksson and Rooth (2014) find that the rate at which an applicant is called back for an interview (i.e. the callback rate) significantly declines with unemployment duration. ${ }^{1}$

When unemployment duration is informative about workers' expected productivity and firms meet several applicants at once, recruiting firms have incentives to rank applicants by duration when calling them for interviews. Note, however, that the firm's ranking reduces the chances to fill a vacancy as those job-seekers who anticipate that they will be discriminated against will apply somewhere else unless wages compensate for the additional unemployment risk. Thus, the ranking of candidates that firms choose will depend on both expected productivity and wages.

In this paper, we analyze the firm's optimal hiring decisions, and how these decisions determine the duration dynamics of callback rates for an interview, exit rates from unemployment and reemployment wages. We show that firms rank applicants by unemployment duration in equilibrium, which endogenizes the ranking mechanism first introduced by Blanchard and Diamond (1994). We also show that our theory rationalizes the observed severe fall of callback and exit rates as well as the mild decline of wages over duration. Furthermore, we find that the ranking mechanism is crucial for these results, and that its quantitative role can be important to explain the evidence.

To explicitly model the ranking strategies of employers, we set up a directed search model of the labor market with two key ingredients. First, skilled workers are both more productive and more likely to be suitable for any job than the unskilled, but information about workers' type is symmetric and incomplete. Second, firms can screen out unsuitable applicants, and can discriminate among observationally different workers both ex-ante through wages and ex-post by deciding on a ranking of the candidates to be tested.

In our model, unobserved heterogeneity together with the firms' testing in the past leads

\footnotetext{
${ }^{1}$ Farber et al. (2017) find no variation of callback rates over unemployment duration for US collegegraduated females aged 35+ for clerical jobs in the U.S. In their comparison with Kroft et al. (2013), they conclude that age and hence working experience may account for the differences.
} 
to sorting as in the seminal paper by Lockwood (1991), i.e. skilled workers leave the unemployment pool faster. As a result, unemployment duration conveys information about expected productivity. Firms set wages to solve the trade-off spelled out above between attracting more applicants and testing them according to a chosen ranking. Notice that if firms committed to a single wage, as in Lang et al. (2005) and Peters (2010), the ranking by unemployment duration would be the obvious optimal decision ex-post, but firms would attract fewer applicants. In contrast, we allow firms to commit to a menu of wages, potentially contingent on expected productivity. Equilibrium wages pay a share of worker's productivity net of the value of the next best candidate, thereby making the most productive applicants the most profitable ones as well as ensuring that all workers obtain their market value when queueing for the job. As a result, the labor market is non-segmented in equilibrium because firms find it optimal to attract workers of all durations to increase their job-filling rate and to save on wages as the presence of more competitors reduces the marginal value of any given worker. Importantly, wages need not monotonically decline over unemployment duration.

Why do exit rates fall as unemployment duration increases? First, because applicants are tested only if no worker with shorter duration either applied for the job or was found to be suitable, thereby leading callback rates for an interview to fall with duration. Second, exit rates also fall due to sorting as the share of skilled workers in the unemployment pool becomes smaller with duration, and hence so does the probability of succeeding at the test. ${ }^{2}$

We then investigate the effects of the firm's ranking decision by comparing to an alternative economy that only differs from the benchmark in that firms are forced to test all applicants. We refer to it as the $N R$ economy. In this alternative setting, callback rates are constant in duration by assumption, and, although firms can still discriminate among observationally different workers through wages, the labor market is segmented in equilibrium. ${ }^{3}$ The elimination of the ranking margin makes it too costly for firms to attract all applicants: the gains from the higher job-filling rates when also attracting workers with longer unemployment spells are offset by the lower expected productivity per filled vacancy and the higher wage costs necessary to compensate the more productive workers for their lower matching rates. When firms can discriminate in favor of the more productive workers

\footnotetext{
${ }^{2}$ Notice that the declining pattern over unemployment duration hinges on the labor market being nonsegmented in equilibrium. If it were segmented to some degree with different submarkets targeting different subsets of unemployment duration, for example because firms could not make offers contingent on productivity like in Peters (2010), then callback rates might exhibit upward jumps when moving from one submarket to the subsequent one as applicants would go from being ranked last to being ranked first.

${ }^{3}$ This is in line with the results obtained in Menzio and Shi (2010) with on-the-job directed search and heterogeneous workers. Furthermore, Lang et al. (2005) and Peters (2010) show that the wage margin is also central for the market to be non-segmented by studying an economy in which firms commit to a single wage but can rank applicants.
} 
instead, such costs do not exist. Likewise, we find that while in our benchmark economy exit rates always fall with duration but wages might be non-monotone, wages in the NR economy continuously fall and the duration dynamics of exit rates are ambiguous.

We evaluate the quantitative properties of our model to gauge how well it can replicate the data, and to illustrate the effects of the firms' ranking decision. We calibrate the model to the U.S. labor market. We target several moments of the duration distribution of exit rates that we construct from the Current Population Survey (CPS), whereas no information from wages and callback rates is used. The simulated data replicates very well the actual distribution of exit rates. In addition, model wages show a declining pattern over unemployment duration very close to the actual one we obtain from the CPS. Callback rates also significantly drop with duration in line with the empirical evidence from the aforementioned field experiments. Moreover, the comparison between the benchmark and the NR equilibrium allocations suggests that ranking strongly amplifies the fall of exit rates along duration, even if the degree of ex-ante heterogeneity is very small.

Our main contribution to the macroeconomic literature is to provide a theory that jointly rationalizes the observed duration patterns of callback rates, exit rates, and wages. As we briefly discuss below, previous work has primarily focused on mechanisms that theoretically explain the decline of job-finding rates along unemployment duration, giving little role to wages and, more generally, to the firms' hiring behavior. In contrast, our theory is based on firm's endogenous ranking induced by sorting, which together with the equilibrium wages firms commit to ensures a non-segmented labor market.

Our ranking result is a form of rational stigma based on the information conveyed by the sorting of unemployed workers as time passes. Lockwood (1991) first modeled rational stigma associated with long-term unemployment as a duration cut-off rule within a random search framework. Two recent pieces in this vein that have a quantitative approach are Jarosch and Pilossoph (2015), who also study the duration dynamics of callback rates, and Doppelt (2015). Search is random and wages do not play an allocative role in these papers since they are derived from a surplus-sharing rule. To gain tractability, firms have all the bargaining power in Lockwood (1991) and Jarosch and Pilossoph (2015), but thereby making reemployment wages constant in duration as in the ranking model of Blanchard and Diamond (1994). In Doppelt (2015), workers learn about their types during both employment and unemployment spells, and, according to his calibration exercise, his stigma mechanism also accounts for a sizable part of the decline in exit rates, with equilibrium wages varying nonmonotonically with duration.

We also contribute to the directed search literature that started with Peters (1991) and 
Moen (1997). Within this literature, ranking as a decision of firms has first been modeled in a static setting by Shi (2002) and Shimer (2005a). ${ }^{4}$ Their primary focus is on the assignment of exogenously heterogeneous workers to a distribution of firms. Instead, we investigate the effects of ranking on the duration dynamics of exit rates and wages when the distribution of expected productivities is endogenous. Furthermore, and in contrast to their models, we argue that the equilibrium allocation is not constrained efficient in our setting due to an intertemporal information externality.

In closely related work, Gonzalez and Shi (2010) analyze an economy with bilateral meetings, where equally productive workers learn about their matching ability (akin to our concept of suitability) from their own search. In contrast to our benchmark model, a segmented labor market arises endogenously because staying unemployed one more period makes workers search for lower wage jobs, which are easier to obtain. Therefore, reemployment wages decline with duration in equilibrium, but exit rates need not fall because of sorting. Flemming (2015) also rationalizes the different sensitivity of exit rates and wages to unemployment duration in a directed search model with learning by doing.

As the assumption of non-sequential search of firms is key for our results, we now briefly summarize the empirical evidence in its support. Using Dutch data, van Ours and Ridder (1992) and Abbring and van Ours (1994) conclude that firms' search is non-sequential, unlike workers' search. Consistent with these findings, van Ommeren and Russo (2009) find that whether firms' search is sequential depends on the search method. In particular, firms search non-sequentially when they use formal methods such as advertising.

Finally, there is a number of theories, complementary to ours, that model a causal effect of duration on exit rates. Workers may get discouraged if the returns to their search fall with unemployment duration due to for example skill attrition (Pissarides (1992)). Fewer job opportunities also arise as unemployment progresses in stock-flow search models (Coles and Smith (1998)) and models with informational networks deteriorating along unemployment duration (Calvo-Armengol and Jackson (2004)).

The paper proceeds as follows. In Section 2, we analyze the benchmark economy and characterize the equilibrium. Section 3 studies the economy without ranking. In Section 4 , we undertake a numerical exercise. Finally, Section 5 concludes and discusses some central assumptions of the model. All proofs and data work are relegated to the Appendix and the Online Appendix.

\footnotetext{
${ }^{4}$ Moen (1999) constructs a model of ranking by education showing that human capital investments prior to matching are undertaken not only to raise future wages, but also employment prospects.
} 


\section{Benchmark Model}

This section presents a directed search model of the labor market in which firms may discriminate among applicants in wages and in the hiring decision.

\section{$2.1 \quad$ Environment}

Time is discrete and continues forever. There is a unit mass of infinitely lived workers and a large continuum of identical firms. The mass of new firms is determined by free entry every period. All agents are risk neutral and discount future payoffs at a common factor $\beta$. The focus of this paper is on the steady-state allocation; hence, time indices are suppressed.

Workers can be either skilled (type $h$ ) or unskilled (type $\ell$ ). There is a mass $\mu \in(0,1)$ of skilled workers, and $1-\mu$ of unskilled workers. Worker types differ both by their market productivity and by their idiosyncratic suitability at any given firm. A type- $i$ job-seeker turns out to be suitable for the job at hand with probability $\lambda_{i}$, with $i \in\{\ell, h\}$. If a worker is not suitable for a given job, the match is not productive and the worker is not hired. A type- $i$ suitable applicant produces $y_{i}$ units of output if hired. We assume that skilled workers have higher chances of being suitable and perform strictly better at the production stage, i.e. $0<\lambda_{\ell}<\lambda_{h} \leq 1$ and $y_{\ell}<y_{h}{ }^{5}$

At the beginning of every period, workers can be either employed or unemployed. The unemployed seek job opportunities and derive utility from home production, $b<y_{\ell}$. Let $\tau$ denote their elapsed duration of unemployment, with $\tau=1,2, \ldots, T$. The value $\tau=T$ stands for unemployment durations greater than or equal to $T$. That is, workers with $\tau=T$ form the homogeneous group of the long-term unemployed. Unemployment duration is public information. ${ }^{6}$ In contrast, there is symmetric incomplete information on the type of the worker. That is, the worker's type is unobservable to both the worker herself and potential employers. Concretely, we make two assumptions on what information is held and acquired in each period to ensure that current unemployment duration is the only observable characteristic.

\footnotetext{
${ }^{5}$ Our suitability concept is in line with the frictions proposed by Petrongolo and Pissarides (2001, p.402). We further comment on this in Section 4. It could also be interpreted as an extreme form of match-specific productivity if output is the product of a match-specific component and worker's time-invariant productivity. We would say that a worker is unsuitable for a given firm if the match-specific term were zero. Suitability may also represent a reduced-form of modeling the scope of tasks at a given job, where skilled workers can do a larger number of tasks. The central assumption in our setting is that skilled workers perform better at the testing stage.

${ }^{6} \mathrm{Kroft}$ et al. (2013) report that $75 \%$ of the actual resumes they collected from job boards did specify the year and month the last job of the candidate had ended.
} 
First, we assume that information about a worker's type reduces to her current unemployment spell. Specifically, the worker herself only knows the information of the current spell. This assumption is made for tractability since the whole labor history of each worker would be informative to herself and recruiting firms otherwise. In support of this, Eriksson and Rooth (2014) find that past, unlike contemporary, unemployment does not drive the recruiting decisions of firms. Second, for tractability and since our main interest is the hiring behavior of firms, we abstract from the worker's learning, which has been modeled in Gonzalez and Shi (2010), and assume that job-seekers do not learn from their own search experience. Thus, a worker's search influences only their contemporaneous prospects in the labor market, but do not affect their continuation value of unemployment if failing to find a job. ${ }^{7}$

Consequently, workers with unemployment duration $\tau$ are all observationally identical, also to themselves. They are suitable for any job with probability

$$
p_{\tau}=\frac{\lambda_{\ell} u_{\ell}(\tau)+\lambda_{h} u_{h}(\tau)}{u_{\ell}(\tau)+u_{h}(\tau)},
$$

where $u_{i}(\tau)$ denotes the measure of unemployed workers of type $i$ and duration $\tau$ at the beginning of a given period. The unemployment distribution $u \equiv\left\{u_{i}(\tau)\right\}_{i, \tau}$ is the aggregate state variable in this economy. The expected match productivity of a suitable candidate of duration $\tau$ is determined by

$$
\bar{y}_{\tau}=\frac{y_{\ell} \lambda_{\ell} u_{\ell}(\tau)+y_{h} \lambda_{h} u_{h}(\tau)}{\lambda_{\ell} u_{\ell}(\tau)+\lambda_{h} u_{h}(\tau)},
$$

Each period consists of four stages: the separation stage, the job-posting stage, the application and meeting stage, and the hiring and production stage. At the beginning of the period, in the first stage, idiosyncratic job-separation shocks hit ongoing matches with probability $\delta$. In those cases, the worker becomes newly unemployed and the firm exits.

The Job-posting Stage. In the second stage, firms decide whether to enter the labor market or not. As is common in the search literature, each firm posts a single vacancy. Firms incur a cost $k$ when posting the vacancy. To ensure existence of equilibria, we assume that vacancy creation costs are low relative to the discounted net productivity of unskilled workers, i.e. $k<\frac{y_{\ell}-b}{1-\beta(1-\delta)}$.

Recruiting firms announce and fully commit to a contract. A contractual offer consists of

\footnotetext{
${ }^{7}$ We discuss the sensitivity of the main results to the information structure in Sections 4.2 and 5.
} 
a menu of wages, which may be contingent on expected productivity. ${ }^{8}$ Let $\omega \equiv\left\{w_{\tau}\right\}_{\tau \leq T} \in$ $\left[0, y_{h}\right]^{T}$ denote a job offer. We shall refer to a submarket as the marketplace defined by a given contract. Two remarks are in order. First, we could allow for wage contracts to specify a continuous function of expected productivity. Since in our model only a finite number of expected productivity levels prevail, we can restrict the set of contracts to finite wage schemes without loss of generality. Second, we index wages by unemployment duration instead of expected productivity. This notation does not mean that wages are contingent on duration, as it may be against the law. This is for notational simplicity as expected productivity given by expression (2) maps bijectively to unemployment duration.

The Application and Meeting Stage. Unemployed workers observe all job offers and submit one application. Search is directed in the sense that those vacancies that promise a higher expected value will attract a larger number of applicants. However, firms set a menu of wages not only to trade off higher wages with a higher rate of applications (extensive margin), but also to influence the relative number of candidates of a given expected productivity (intensive margin).

Meetings are multilateral in the sense that any given firm may receive several applications. As is standard to assume in the literature for large economies, (observationally) identical workers use identical mixed application strategies, and, hence, the realized number of applications a firm receives for any given unemployment duration is a Poisson random variable under the assumption that actual applications are independent across workers. The key characteristic of a multilateral meeting technology is that it enables firms to compare applicants.

The Hiring and Production Stage. In the hiring stage, firms make three decisions if receiving any application. First, they rank candidates according to their expected profitability. Second, they test those who are ranked first. Third, they select a suitable applicant, if there is any. In this last step, firms are assumed to randomize among suitable workers who are observationally identical (i.e. with the same unemployment duration), leading to the so-called coordination frictions. If no candidate is suitable, then they continue testing in the chosen order. The firm vanishes if there is no suitable candidate queueing for the job.

Firms have access to a simple testing technology: A firm observes a private, match-specific signal, which perfectly identifies unsuitable matches. Unsuitable candidates are discarded as

\footnotetext{
${ }^{8}$ In particular, wages cannot be contingent on ex-ante unobservables such as the ex-post revealed actual productivity or the outcome of the meeting process (that is, e.g., how many applications the firm received of each type). We think of those events as unverifiable by a third party and therefore non-enforceable.
} 
the match turns out to be unproductive. Other than determining suitability, firms have no means to identify the type of the applicants when making the hiring decision. We assume that the test outcome is not verifiable and cannot be traded. Thus, neither workers nor other firms learn the private signals of any given firm. Furthermore, the testing expenses are included in the vacancy creation cost $k$.

Firms decide on an order to start testing applicants. ${ }^{9}$ Formally, a firm sets a ranking rule $\sigma$. This ordering must be such that, for any $\tau, \tau^{\prime} \in\{1, \ldots, T\}$,

$$
\sigma(\tau)<\sigma\left(\tau^{\prime}\right) \text { iff either } J_{\tau}(\omega)>J_{\tau^{\prime}}(\omega) \text { or } J_{\tau}(\omega)=J_{\tau^{\prime}}(\omega) \text { and } \tau<\tau^{\prime} \text {, }
$$

where $J_{\tau}(\omega)$ stands for the type- $\omega$ firm's expected discounted value when filling the vacancy with a suitable worker of duration $\tau$. We have imposed that if two different durations correspond to the same expected profitability, then workers with the shorter spell are ranked higher by assumption. For a given value of the state variable $u$, the permutation $\sigma$ is bijective by construction.

We are interested in the equilibrium allocation in which firms rank candidates by unemployment duration. Therefore, for expositional simplicity, we guess that the ranking rule $\sigma(\tau)=\tau$ is consistent with the profit-maximizing behavior of firms, and, later on, Proposition 2.3 will verify this guess. The intuition is that expected productivity declines with unemployment duration irrespective of the ranking rule firms have chosen in the past as the more productive workers are more likely to leave unemployment at any duration. Thus, our guess on the optimal ranking rule must be read as follows: firms rank candidates by expected productivity because the more productive applicants are also the more profitable ones. All agents rationally anticipate that recruiting firms will optimally rank workers by expected productivity (or, equivalently, duration) at any point in time. Finally, production takes place. The worker and all other agents in the economy only observe the hiring decision. ${ }^{10}$

Matching Probabilities. A firm posting a job $\omega$ expects $q_{\tau}(\omega)$ suitable applicants of duration $\tau$. To simplify notation, we will omit the dependence of the expected queue length

\footnotetext{
${ }^{9}$ Since testing costs are included in the vacancy creation costs $k$, firms could test all applicants at once instead of proceeding according to some order, and then rank suitable candidates by profitability. The economy that results from this alternative interpretation is completely equivalent to ours, except for the fact that the rate at which an applicant is called back for an interview would be 1 for all applicants by construction. However, our setting can be defended on the grounds that a tiny testing cost would make firms establish some order in the testing process.

${ }^{10}$ Consistent with our information assumptions, we can assume that either the actual worker's productivity is never learned by employers, or it is instantaneously learned upon hiring but firing is not allowed because of full commitment.
} 
$q$ on the contract $\omega$ hereafter, unless needed for clarity. Define $q^{\tau} \equiv\left(q_{1}, q_{2}, \ldots, q_{\tau}\right)$. For each firm, the probability of filling a job $\omega$ with a suitable worker of duration $\tau$ is

$$
\eta_{\tau}\left(q^{\tau}\right)=e^{-\sum_{\tau^{\prime}<\tau} q_{\tau^{\prime}}}\left(1-e^{-q_{\tau}}\right)
$$

The first factor of this expression stands for the Poisson probability that no worker with a higher ranking than a candidate of duration $\tau$ either applies to the firm or, if applies, is found suitable for the job. The second term is the Poisson probability that the firm receives at least one suitable application from workers of duration $\tau$. Note that this expression captures both the firm's ranking strategy and the fact that unsuitable workers are never hired.

Since the measures of newly employed workers and filled vacancies of each duration must coincide, it must be the case that $\nu_{\tau}\left(q^{\tau}\right) q_{\tau}=\eta_{\tau}\left(q^{\tau}\right)$, where $\nu_{\tau}\left(q^{\tau}\right)$ denotes the job-finding probability for a worker of duration $\tau$ conditional on applying to a type- $\omega$ firm and being suitable for the job. That is,

$$
\nu_{\tau}\left(q^{\tau}\right)=e^{-\sum_{\tau^{\prime}<\tau} q_{\tau^{\prime}}} \frac{1-e^{-q_{\tau}}}{q_{\tau}} .
$$

Therefore, the actual matching probability for a worker of duration $\tau$ is then defined as

$$
h_{\tau}\left(q^{\tau}\right)=p_{\tau} \nu_{\tau}\left(q^{\tau}\right)=e^{-\sum_{\tau^{\prime}<\tau} q_{\tau^{\prime}}} p_{\tau} \frac{1-e^{-q_{\tau}}}{q_{\tau}}
$$

The exit rate from unemployment has three components. The first factor incorporates the firm's ranking strategy. We refer to it as the callback rate as it is the probability of being called for an interview, which occurs if no suitable worker with a shorter spell queued up for the same job. The second term captures how the composition of the unemployment pool evolves with unemployment duration, i.e. the sorting mechanism. The third term results from the standard coordination frictions among applicants of duration $\tau$.

Value Functions. Let us proceed with the value functions of workers and firms. An employed worker derives utility from wages until the arrival of an idiosyncratic job-termination shock, which occurs with probability $\delta$. Her value function is defined by

$$
E_{\tau}(\omega)=w_{\tau}+\beta\left(\delta U_{1}+(1-\delta) E_{\tau}(\omega)\right)
$$

An unemployed worker of duration $\tau$ has value $U_{\tau}$. She may apply to any posted job offer $\omega$, and becomes employed with probability $h_{\tau}\left(q^{\tau}(\omega)\right)$, in which case she receives the value 
$E_{\tau}(\omega)$. Otherwise, she produces $b$ at home and remains unemployed one more period. A worker of duration $\tau$ applies to a job offering contract $\omega$ if the expected value derived from $\omega$ equates the unemployment value $U_{\tau}$ for a positive $q_{\tau}(\omega)$. Otherwise, no worker of duration $\tau$ applies to such a job, and $q_{\tau}(\omega)=0$. Expectations about $q_{\tau}(\omega)$ are thus pinned down on and off the equilibrium. The following equilibrium condition summarizes this logic.

$$
\begin{array}{ccl}
U_{\tau} \quad \geq \quad h_{\tau}\left(q^{\tau}(\omega)\right)\left(E_{\tau}(\omega)-b-\beta U_{\tau+1}\right)+b+\beta U_{\tau+1} \\
\text { and } \quad q_{\tau}(\omega) \geq 0, \quad \text { with complementary slackness, }
\end{array}
$$

where $U_{T+1} \equiv U_{T}$.

Now, the expected value of a firm offering contract $\omega$ and filling its vacancy with a worker of duration $\tau$ amounts to the worker's expected productivity net of wages until the arrival of a job-destruction shock, when it exits the economy. Its value function is defined by

$$
J_{\tau}(\omega)=\bar{y}_{\tau}-w_{\tau}+\beta(1-\delta) J_{\tau}(\omega) \text {. }
$$

Firms write contracts to maximize profits. A firm incurs a recruitment cost $k$ when posting a vacancy. A job with contract $\omega$ is filled with a candidate of duration $\tau$ with probability $\eta_{\tau}\left(q^{\tau}(\omega)\right)$, and then the firm obtains the expected value $J_{\tau}(\omega)$. The value function of a vacant firm is then defined by

$$
V=\max _{\omega}\left\{-k+\sum_{\tau=1}^{T} \eta_{\tau}\left(q^{\tau}(\omega)\right) J_{\tau}(\omega)\right\} .
$$

\subsection{Equilibrium}

Next, we define the symmetric directed search equilibrium in the steady state. We use the term symmetric to refer to the case where identical agents make identical decisions. In particular, all firms commit to the same contract.

Definition 1 A steady state symmetric directed search equilibrium consists of a distribution of unemployed workers $u \in[0,1]^{2 \times T}$, value functions $J_{\tau}, E_{\tau}:\left[0, y_{h}\right]^{T} \rightarrow \mathcal{R}_{+}$, and $V, U_{\tau} \in$ $\mathcal{R}_{+}, \forall \tau \in\{1, \ldots, T\}$, a menu of contracts $\omega \in\left[0, y_{h}\right]^{T}$, an expected queue length function $Q \equiv\left(Q_{\tau}\right)_{\tau}:\left[0, y_{h}\right]^{T} \rightarrow \mathcal{R}_{+}{ }^{T}$, and the ranking rule $\sigma(\tau) \equiv \tau$ such that:

i) Given $Q$ and $u$, the value functions satisfy the Bellman equations (7)-(10).

ii) Firms' profit maximization and zero-profit condition: 
- Given $u$ and $\omega$, the ranking rule $\sigma$ satisfies condition (3).

- Given $\left(U_{\tau}\right)_{\tau}, Q$, and $u, \omega$ is the profit-maximizing contract, and expected profits become zero at $\omega$ :

$$
\forall \omega^{\prime} \in\left[0, y_{h}\right]^{T}, \quad-k+\sum_{\tau=1}^{T} \eta_{\tau}\left(Q\left(\omega^{\prime}\right)\right) J_{\tau}\left(\omega^{\prime}\right) \leq V=0 \text {, with equality for } \omega^{\prime}=\omega
$$

iii) Workers direct their search:

$\forall \omega^{\prime} \in\left[0, y_{h}\right]^{T}$ and $\forall \tau \in\{1, \ldots, T\}, Q_{\tau}\left(\omega^{\prime}\right)$ satisfies the complementary slackness condition (8).

iv) Recursivity condition:

Let $q_{\tau} \equiv Q_{\tau}(\omega)$. The distribution of workers recursively satisfies

$$
\begin{aligned}
u_{i}(\tau) & =u_{i}(\tau-1)\left(1-\lambda_{i} \nu_{\tau-1}\left(q^{\tau-1}\right)\right), \forall \tau \in\{2, \ldots, T-1\}, \\
u_{i}(T) & =u_{i}(T-1)\left(1-\lambda_{i} \nu_{T-1}\left(q^{T-1}\right)\right)+u_{i}(T)\left(1-\lambda_{i} \nu_{T}\left(q^{T}\right)\right), \\
\text { and } & \\
u_{i}(1) & =\delta\left(\mu_{i}-\sum_{\tau=2}^{T} u_{i}(\tau)\right),
\end{aligned}
$$

v) Resource constraints:

$$
\frac{q_{\tau}}{\sum_{i} \lambda_{i} u_{i}(\tau)}=\frac{q_{1}}{\sum_{i} \lambda_{i} u_{i}(1)}, \quad \text { if } q_{\tau} \neq 0
$$

Firms maximize profits, which equal zero in equilibrium because of free entry. To rank applicants by unemployment duration is profit maximizing. The third equilibrium condition is required to pin down rational expectations on queue lengths out of the equilibrium. This condition determines the expected queue length for any given contract attractive to workers by making them indifferent between the equilibrium contract and this other offer.

The aggregate state variable $u$ is determined by the history of all agents' equilibrium decisions. The Law of Large Numbers ensures that a measure $u_{i}(\tau) \lambda_{i} \nu_{\tau}\left(q^{\tau}\right)$ of type $i$ workers with duration $\tau$ becomes employed. Thus, the fourth condition determines the law of motion for the state variable. Finally, the set of constraints (12) result from the requirement that in a symmetric equilibrium the ratio of suitable workers to the queue length must be the same across durations. 
We now rewrite expression (10) as the profit maximization problem of a representative firm. For any given pair $\left(u,\left(U_{\tau}\right)_{\tau}\right)$, the firm's program is

$$
\begin{array}{cc}
\max _{\omega, q^{T}} & \sum_{\tau} \eta_{\tau}\left(q^{\tau}\right) J_{\tau}(\omega)-k \\
\text { s. to } & p_{\tau} \eta_{\tau}\left(q^{\tau}\right)\left(E_{\tau}(\omega)-b-\beta U_{\tau+1}\right)+q_{\tau}\left(b+\beta U_{\tau+1}\right)=q_{\tau} U_{\tau}, \quad \forall \tau
\end{array}
$$

That is, firms choose the pair $\left(\omega, q^{T}\right)$ that maximizes their profits, rationally anticipating the relationship between wages and queue lengths that arises from the optimal search behavior of workers. Indeed, the constraints are the equilibrium complementary slackness conditions (8). For later use, it is convenient to define $\Delta_{\tau} \equiv J_{\tau}(\omega)+E_{\tau}(\omega)-b-\beta U_{\tau+1}=\frac{\bar{y}_{\tau}+\beta \delta U_{1}}{1-\beta(1-\delta)}-b-\beta U_{\tau+1}$. It is the net value of a match with a worker of duration $\tau$. The following proposition states that there exists a solution for the firm's problem. We also provide a sufficient condition for uniqueness. Moreover, we show that it is optimal for firms to attract applicants of all durations in equilibrium.

Proposition 2.1 Given the state variable $u$ and the unemployment values $U_{\tau}$ for $\tau \in$ $\{1, \ldots, T\}$, there exists a solution $\left(\omega, q^{T}\right)$ for the firm's program. If $\Delta_{\tau}$ falls with duration, then the firm's problem has a unique solution. Furthermore, in any symmetric equilibrium, all queue lengths are strictly positive, $q_{\tau}>0 \forall \tau$.

The next proposition establishes existence of a symmetric equilibrium by showing that it can be formulated as a fixed point problem.

Proposition 2.2 There exists a symmetric directed search equilibrium.

This result together with Proposition 2.1 implies that workers of all unemployment durations search in the same labor market. Firms find it profitable to attract all workers in order to both increase the probability of filling their vacancies and extract a higher share of the surplus from a given match. The latter relies on the firms' ability of treating different applicants differently through wages and ranking. To see this, notice that, because of the ranking by expected productivity, the presence of workers with longer unemployment durations queueing for the job hedges the firm's risks of ending up with the vacancy not filled by any worker of duration $\tau$. As a result, the standard trade-off between wages and job-filling rates is weakened for applicants with shorter durations, so that firms lower the wage promises to these workers.

A natural question is why there is no profitable deviation targeting only a subset of workers. This is a fair critique to random search models with ranking wherein all job-seekers 
are concentrated in a single market by assumption, like Blanchard and Diamond (1994). See e.g. Shi (2002). The intuition underlying this critique is that if workers could direct their search, the ranking strategy would no longer take place in equilibrium. This is because firms could profitably deviate by targeting only workers with a given duration $\tau$ and saving on wages by offering them a higher job-finding rate. In contrast, this logic does not hold in our setting because the deviating firms would find it more profitable to attract not only all workers with durations longer than $\tau$ for the two reasons listed above, but also workers with shorter durations as they are more profitable. Therefore, deviations with such a recruiting strategy cannot be profitable. ${ }^{11}$

\subsection{Equilibrium Duration Dynamics}

In this section, we look at the duration dynamics of the equilibrium variables. A key result is stated in the following proposition: although the distribution of expected productivities is an endogenous outcome, expected productivity falls with unemployment duration regardless of how firms ranked candidates in the past. The underlying intuition is that skilled candidates are more likely to be suitable for any job than their unskilled counterparts at any duration and, hence, the relative mass of skilled job-seekers declines as the duration of unemployment increases. Therefore, ordering candidates by expected productivity is equivalent to ordering them by unemployment duration. It turns out that the most productive candidates are the most profitable ones in equilibrium as the fall in the expected productivity is not offset by the wage changes over duration. We give more intuition for why wages decline by less than expected productivity when we discuss equilibrium wages further below in this section. As a result, it is optimal for firms to rank candidates by their unemployment duration, confirming that the imposed ranking rule is consistent with profit-maximizing behavior.

Proposition 2.3 Independently of the ranking rule, $\bar{y}_{\tau}$ falls with unemployment duration $\tau$. Furthermore, the value of an active firm $J_{\tau}(\omega)$ declines with $\tau$ in equilibrium.

The continuous decline in expected productivity suggests that the employment prospects of a worker also deteriorate over time. Proposition 2.4 shows that the equilibrium unemployment value, $U_{\tau}$, declines with duration. More importantly for us, callback rates for an interview and exit rates from unemployment also fall with duration. Both rates fall because of firms' ranking decision, but also because of the labor market being non-segmented in equilibrium. To see this, consider a labor market segmented by different subsets of unemployment

\footnotetext{
${ }^{11}$ To see this formally, notice that deviating firms must also solve problem (13) because its formulation allows for workers of a given duration $\tau$ not being targeted (i.e. $q_{\tau}=0$ ).
} 
duration. If firms ranked workers by duration given this market structure, callback rates would exhibit upward jumps as workers of duration $\tau$ would be ranked last in one submarket whereas workers of duration $\tau+1$ would be ranked first in another submarket. Moreover, since the probability of being suitable would monotonically decline with duration, the slope of the duration profile of exit rates would be ambiguous at those points.

It is worth underscoring that sorting is the primary factor underlying the negative relationship between unemployment duration and both callback and exit rates. To be more precise, the ranking by expected productivity relies on the information flows generated by the sorting mechanism. If there were no sorting, i.e. if $\lambda_{\ell}=\lambda_{h}$, the probability $p_{\tau}$ would be constant and unemployment duration would not be informative about the applicants' expected productivity, thereby eliminating the rational grounds of ranking. The equilibrium allocation would not differ from the standard setting with homogeneous workers, in which all agents meet in the same market and exit rates and re-employment wages are constant in unemployment duration. However, arbitrarily small differences in suitability rates across types would make the component $p_{\tau}$ roughly constant over unemployment duration, while they would translate into large falls in callback and exit rates because of the amplification through ranking. Likewise, if there were no productivity differences across workers $\left(y_{\ell}=y_{h}\right)$ and, hence, firms did not rank applicants, exit rates would still decline because of sorting as $p_{\tau}$ would continuously fall with duration.

Proposition 2.4 The callback rate, the job-finding rate and the value of unemployment for a worker fall with unemployment duration.

We now turn to the determination of equilibrium wages. Wages obtain directly by manipulating the first order conditions of the firms' problem (13) and the complementary slackness conditions (8). They are determined by the following expression.

$$
\frac{w_{\tau}+\beta \delta U_{1}}{1-\beta(1-\delta)}=\frac{q_{\tau} e^{-q_{\tau}}}{1-e^{-q_{\tau}}}\left(\Delta_{\tau}-\sum_{\tau^{\prime}=\tau+1}^{T} e^{-\sum_{\tau^{\prime \prime}=\tau+1}^{\tau^{\prime}-1} q_{\tau^{\prime \prime}}}\left(1-e^{-q_{\tau^{\prime}}}\right) \Delta_{\tau^{\prime}}\right)+b+\beta U_{\tau+1}
$$

where $U_{T+1} \equiv U_{T}$. The left hand side of this expression is the employment value $E_{\tau}(\omega)$. In search models, workers are paid a share of the match surplus on top of their unemployment value. In directed search models, the worker's share is determined in equilibrium as the elasticity of the job-filling probability, which is the fraction in the first term on the right hand side of equation (14). In our setting with multilateral meetings, it can also be interpreted as the probability that the applicant is the only one of duration $\tau$ conditional on the firm receiving at least one suitable application of that duration. This term is multiplied by the 
net value of the match minus the expected net value derived from any other potential match with workers of higher durations. ${ }^{12}$ In other words, workers are rewarded according to their marginal value relative to the next best alternative. Now, for workers of low durations the value of this next best alternative is larger than for workers of high durations, which leads to a wage profile that is less steep than the productivity profile. This explains the result in Proposition 2.3 that ex-post profits decline in duration.

Do equilibrium wages decline with unemployment duration? They need not. The following proposition claims that wages do not always fall with duration if worker types are sufficiently similar in at least one dimension.

Proposition 2.5 There exists $\epsilon>0$ such that $w_{T}>w_{T-1}$ if either $y_{h}-y_{\ell}<\epsilon$ or $\lambda_{h}-\lambda_{\ell}<\epsilon$.

To better understand the wage dynamics, consider the $T=2$ economy, in which jobseekers can be either short-term $(\tau=1)$ or long-term $(\tau=T=2)$ unemployed. We rewrite equation (14) for the $T=2$ case as

$$
E_{1}(\omega)=\frac{q_{1} e^{-q_{1}}}{1-e^{-q_{1}}}\left(\Delta_{1}-\left(1-e^{-q_{2}}\right) \Delta_{2}\right)+b+\beta U_{2}, \quad E_{2}(\omega)=\frac{q_{2} e^{-q_{2}}}{1-e^{-q_{2}}} \Delta_{2}+b+\beta U_{2}
$$

It follows that

$$
\begin{aligned}
w_{1} \geq w_{2} & \Leftrightarrow \frac{q_{1} e^{-q_{1}}}{1-e^{-q_{1}}}\left(\Delta_{1}-\left(1-e^{-q_{2}}\right) \Delta_{2}\right) \geq \frac{q_{2} e^{-q_{2}}}{1-e^{-q_{2}}} \Delta_{2} \\
& \Leftrightarrow \frac{q_{1} e^{-q_{1}}}{1-e^{-q_{1}}}\left(\frac{\bar{y}_{1}-\bar{y}_{2}}{1-\beta(1-\delta)}\right) \geq e^{-q_{2}} \Delta_{2}\left(\frac{q_{2}}{1-e^{-q_{2}}}-\frac{q_{1} e^{-q_{1}}}{1-e^{-q_{1}}}\right)
\end{aligned}
$$

Consider first the limit case: either $y_{\ell}=y_{h}$ or $\lambda_{\ell}=\lambda_{h}$. Then, the left hand side of the inequality is zero because $\bar{y}_{1}=\bar{y}_{2}$. However, the right hand side is strictly positive because the first term within the parenthesis is greater than one whereas the second is lower than one. Thus, $w_{1}<w_{2}$. Consider now an arbitrarily small gap in either productivity or suitability rates between types so that the difference in expected productivity between shortand long-term workers $\bar{y}_{1}-\bar{y}_{2}$ is also arbitrarily close to zero. Then, the above inequality is violated, and wages are higher for the long-term unemployed.

\footnotetext{
${ }^{12}$ Notice that if there were another applicant of duration $\tau$, the marginal value of the worker would be zero. Since contractual offers cannot be made contingent on the number of applications received, firms commit to the expected marginal value of the applicant by averaging over these two events. As Shimer (2005a) and others have pointed out, equilibrium wages would equal the expected compensation a worker would obtain if the firm sold the job to the worker by using a second price sealed bid auction.
} 
The intuition is as follows. If worker types were sufficiently close in either dimension and were perfectly observable, then their unemployment values should also be close. Since in our setting types are not observable, but unemployment duration is, then the value of unemployment could not fall significantly with unemployment duration in that case. As firms discriminate against long-term unemployed workers in the hiring stage in equilibrium, $w_{2}$ would have to be larger than $w_{1}$ to compensate for the lower matching probability. Notice that this result of increasing wages holds even if types are very dissimilar in the other dimension because this large difference is not translated into productivity differences over unemployment duration. That is, if skilled workers were much less likely to be screened out, but almost equally productive as the unskilled, expected productivity would decline very little as the productivity of the unskilled would be a lower bound. Instead, if suitability rates were arbitrarily close and skilled workers were much more productive, the impact of sorting would be very weak and the expected productivity decline would also be tiny.

It is apparent from the previous reasoning that expected productivity must fall sufficiently with unemployment duration to make wages decline. This decline in expected productivity requires sufficiently large differences in both productivity and suitability rates between worker types. However, this may not suffice for the $T>2$ case as applicants of longer durations may also queue for the same job and, hence, some degree of convexity in the endogenous distribution of expected productivities seems necessary for falling wages. This is because firm's ranking decision implies that workers are worth a share of their marginal value instead of their productivity, and marginal values may not be monotonically decreasing even if expected productivities are. Our numerical work for high $T$ values indicates that wages monotonically decline for a broad range of parameter values, although not in all instances. ${ }^{13}$

To conclude, unlike in models with bilateral meetings, where workers get a share of their productivity net of their own outside option, wages in our model reward the workers' productivity net of workers outside option and the firm's next best alternative. As a result, the ranking mechanism in our framework with multilateral meetings compresses wage differences across workers of different durations.

\section{No-ranking Economy}

In the benchmark economy, firms have two instruments to discriminate among observationally different candidates. They can offer different wages to different candidates, but also

\footnotetext{
${ }^{13}$ While the effect of the next best worker on wages can be significant, the reduction in value due to the long-term unemployed applicants, which have a low matching probability, tends to be quite small. Blanchard and Diamond (1994) find a similar result.
} 
rank them according to expected profitability in the hiring stage. To understand the importance of ranking, we study an alternative setting, to which we refer as the NR economy, wherein firms can only use wages as a discrimination instrument, and are forced to test all candidates and randomize among suitable applicants in the hiring stage. Callback rates are, thus, constant over unemployment duration by construction. Moreover, recruiting firms that attract applicants of different expected productivities must form rational expectations about the proportions of each type. Other than that, the economy is identical to the benchmark.

The probability of becoming employed conditional on being suitable for the job $\omega$ does not vary with the worker' unemployment duration by assumption, and, hence, it amounts to $\nu(q(\omega))=\frac{1-e^{-q(\omega)}}{q(\omega)}$, where $q(\omega)$ denotes the expected number of applicants to job $\omega$. See the Online Appendix for further details. The exit rate from unemployment still depends on the length of the unemployment spell because of the sorting factor, $h_{\tau}(q(\omega))=p_{\tau} \nu(q(\omega))$. Consistently, the probability of filling a job equals $\eta(q(\omega))=1-e^{-q(\omega)}$.

When posting job $\omega$, firms form rational expectations about the probability of filling the vacancy with a worker of duration $\tau$. Let $\rho(\omega) \equiv\left(\rho_{1}(\omega), \ldots, \rho_{T}(\omega)\right)$ be a point of the unit (T-1)-simplex that denotes such expectations. The expected value of a vacant firm is

$$
V=\max _{\omega}\left\{-k+\eta(q(\omega)) \sum_{\tau} \rho_{\tau}(\omega) J_{\tau}(\omega)\right\}
$$

Likewise, the unemployment value for a worker with unemployment duration $\tau$ applying to job $\omega$ is

$$
\begin{aligned}
& h_{\tau}(q(\omega))\left(E_{\tau}(\omega)-b-\beta U_{\tau+1}\right)+b+\beta U_{\tau+1} \leq U_{\tau}, \quad \text { and } \rho_{\tau}(\omega) \geq 0 \text {, } \\
& \text { with complementary slackness, and } q(\omega)>0 \text { iff } \max _{\tau} \rho_{\tau}(\omega)>0
\end{aligned}
$$

Notice that these two expressions are the counterparts of expressions (10) and (8) in the NR economy, respectively, and only differ in the object $\rho$. The expectations on the queue length $q$ and proportions $\rho$ are also pinned down off the equilibrium path to help determine the equilibrium allocation.

\subsection{No-ranking Equilibrium}

We next define a symmetric equilibrium in the steady state. We use the term symmetric to refer to the allocation wherein workers who are observationally identical (i.e. workers with the same unemployment duration) make identical decisions. However, firms may commit to different contracts, unlike in the benchmark, and, hence, there may be a number of 
submarkets open in equilibrium.

Definition 2 A steady state no-ranking symmetric directed search equilibrium consists of a distribution of unemployed workers $u \in[0,1]^{2 \times T}$, value functions $J_{\tau}, E_{\tau}:\left[0, y_{h}\right]^{T} \rightarrow \mathcal{R}_{+}$, and $V, U_{\tau} \in \mathcal{R}_{+}, \forall \tau \in\{1, \ldots, T\}$, a distribution of vacancies $\mathcal{F}$ over the set $\left[0, y_{h}\right]^{T}$ with support $\Omega$, an expected queue length function $Q:\left[0, y_{h}\right]^{T} \rightarrow \mathcal{R}_{+}$, and an expectation function $\rho:\left[0, y_{h}\right]^{T} \rightarrow\left\{x \in[0,1]^{T} \mid \sum_{t} x_{t}=1\right\}$ such that:

i) Given $Q$ and $u$, the value functions satisfy the Bellman equations (7), (9), (16) and (17).

ii) Firms' profit maximization and zero-profit condition:

Given $\left(U_{\tau}\right)_{\tau}, Q, \rho$ and $u$, firms maximize profits at any contract in $\Omega$, and expected profits are zero:

$$
\forall \omega \in\left[0, y_{h}\right]^{T}, \quad-k+\eta(q(\omega)) \sum_{\tau} \rho_{\tau}(\omega) J_{\tau}(\omega) \leq V=0, \text { with equality for } \omega \in \Omega
$$

iii) Workers direct their search:

$\forall \omega \in\left[0, y_{h}\right]^{T}$ and $\forall \tau \in\{1, \ldots, T\}, Q(\omega)$ and $\rho(\omega)$ satisfy the complementary slackness condition (17).

$\forall \omega \in \Omega, Q(\omega)>0$, and $\exists \tau \in\{1, \ldots, T\}$ such that $\rho_{\tau}(\omega)>0$.

iv) Recursivity condition:

The distribution of workers recursively satisfies

$$
\begin{aligned}
u_{i}(\tau)= & u_{i}(\tau-1)\left(1-\lambda_{i} \int_{\Omega} \rho_{\tau}(\omega) \nu(Q(\omega)) d \mathcal{F}(\omega)\right), \forall \tau \in\{2, \ldots, T-1\}, \\
u_{i}(T)= & u_{i}(T-1)\left(1-\lambda_{i} \int_{\Omega} \rho_{T-1}(\omega) \nu(Q(\omega)) d \mathcal{F}(\omega)\right)+ \\
& +u_{i}(T)\left(1-\lambda_{i} \int_{\Omega} \rho_{T}(\omega) \nu(Q(\omega)) d \mathcal{F}(\omega)\right),
\end{aligned}
$$

and

$$
u_{i}(1)=\delta\left(\mu_{i}-\sum_{\tau=2}^{T} u_{i}(\tau)\right)
$$

v) Market clearing:

$$
\int_{\Omega} \rho_{\tau}(\omega) Q(\omega) d \mathcal{F}(\omega)=\lambda_{\ell} u_{\ell}(\tau)+\lambda_{h} u_{h}(\tau)
$$


When designing profit-maximizing contracts, firms form rational expectations about both the queue length and the proportion of suitable applicants from each duration that apply to the job. The third equilibrium condition establishes that the expected queue length at any job $\omega$ equals the maximum of the $q$ values that guarantees workers of any duration $\tau$ to obtain the unemployment value $U_{\tau}$ if applying to contract $\omega$. The intuition is as follows. Consider workers of two different unemployment durations $\tau$ and $\tau^{\prime}$ applying to contract $\omega$, and let $q$ and $q^{\prime}$, with $q<q^{\prime}$, denote the queue lengths that secure their unemployment value. Then, if $q$ were the equilibrium expected queue length, there would be a flow of workers of duration $\tau^{\prime}$ applying to $\omega$, increasing the ratio of applicants per vacancy, and workers of duration $\tau$ would no longer apply. Moreover, firms form rational expectations about the proportion of suitable applicants from each duration that apply to the job because the labor market may be segmented, unlike in the benchmark. The last equilibrium condition ensures that the sum of suitable applicants of a given duration across markets must be equal to the total supply of suitable unemployed workers of that duration.

We now turn to the firm's problem. Given the vector $\left(u,\left(U_{\tau}\right)_{\tau}\right)$, a firm chooses the combination of an expected queue length and a wage scheme to maximize its expected discounted profits. By choosing this pair, the firm is indeed deciding on what type of workers to target. Since it may not be optimal for the firm to attract all workers as it will not be able to discriminate among them ex-post, the optimal application condition (17) will only hold for the targeted durations. We can rewrite the counterpart of the firm's problem (13) as

$$
\begin{aligned}
\max _{q,\left\{w_{\tau}, r_{\tau}\right\}_{\tau}} & \eta(q) \sum_{\tau} r_{\tau} \frac{\bar{y}_{\tau}-w_{\tau}}{1-\beta(1-\delta)} \\
\text { s. to } & p_{\tau} \eta(q) \frac{w_{\tau}+\beta \delta U_{1}}{1-\beta(1-\delta)} \geq q U_{\tau}-q\left(1-p_{\tau} \nu(q)\right)\left(b+\beta U_{\tau+1}\right), \forall \tau \mid r_{\tau}>0 \\
& r_{\tau} \geq 0, \sum_{\tau} r_{\tau}=1
\end{aligned}
$$

Notice that this problem is linear in $r_{\tau}$. Profit-maximization requires that no firm attracts workers of a duration $\tau$ if the expected profits are below the maximum. That is, a firm will obtain $M \equiv \max _{\tau} M_{\tau}$ by making $r_{\tau}=0$ and $w_{\tau}=0$ for all $\tau$ such that $M_{\tau}<M$, where

$$
\begin{aligned}
M_{\tau} \equiv \max _{q_{\tau}, w_{\tau}} & \eta(q) \frac{\bar{y}_{\tau}-w_{\tau}}{1-\beta(1-\delta)} \\
& \text { s. to } \quad p_{\tau} \eta\left(q_{\tau}\right) \frac{w_{\tau}+\beta \delta U_{1}}{1-\beta(1-\delta)} \geq q_{\tau} U_{\tau}-q_{\tau}\left(1-p_{\tau} \nu\left(q_{\tau}\right)\right)\left(b+\beta U_{\tau+1}\right)
\end{aligned}
$$


Thus, the firm's problem reduces to allocating a positive weight to duration $\tau$ if the net returns from attracting only workers of duration $\tau, M_{\tau}$, attain the maximum $M$ and a zero weight otherwise. If workers of different durations yielded the maximum return, then firms would be indifferent between attracting applicants from one or several durations. Submarkets are linked both through the recursivity condition of the state variable $u$, which helps to determine both the expected productivity $\bar{y}_{\tau}$ and the suitability probability $p_{\tau}$, and the unemployment continuation values $\left\{U_{\tau}\right\}_{\tau}$.

The following proposition states existence of an equilibrium allocation with a labor market fully segmented by unemployment duration, and characterizes the equilibrium. Notice that any other symmetric equilibrium must be observationally equivalent to this one. It also states that there is no equilibrium with a single labor market because the $\tau=T$ and $\tau=T-1$ workers will always search in different submarkets as ex-post profits are strictly lower if forming a match with the former than with the latter.

Proposition 3.1 There exists an equilibrium in which the labor market is segmented by unemployment duration and $\Omega=\left\{\omega_{1}, \ldots, \omega_{T}\right\}$, where $\omega_{\tau}$ consists of a zero wage for all durations but $\tau$. The equilibrium queue length $q_{\tau}$ and wage $w_{\tau}$ in submarket $\tau$ satisfy the following conditions

$$
\begin{aligned}
\frac{w_{\tau}+\beta \delta U_{1}}{1-\beta(1-\delta)} & =\frac{e^{-q_{\tau}} q_{\tau}}{1-e^{-q_{\tau}}} \Delta_{\tau}+b+\beta U_{\tau+1} \\
k & =\eta\left(q_{\tau}\right)\left(1-\frac{e^{-q_{\tau}} q_{\tau}}{1-e^{-1_{\tau}}}\right) \Delta_{\tau}
\end{aligned}
$$

Furthermore, there does not exist an equilibrium with a non-segmented market.

The equilibrium equation (23) is the zero-profit condition, whereas expression (22) is the standard determination of wages and is derived from the first order condition of program (21). Notice the difference between the benchmark equilibrium wages, determined in expression (14), and the wages in the NR economy. When ranking is allowed, wages are reduced relative to the NR wages by the expected value of filling the vacancy with a suitable candidate of a longer unemployment duration. Therefore, conditional on the same queue lengths, equilibrium wages in the benchmark would be lower than in the NR economy.

\subsection{Equilibrium Duration Dynamics}

We turn now to study the dynamics of the equilibrium variables over unemployment duration. Proposition 2.3 states that expected productivity declines with duration. However, 
we show below that ex-post profits $J_{\tau}$ need not decline with $\tau$ in the NR economy. Still, a worker's unemployment value falls as the length of the unemployment spell increases if sorting takes place. Moreover, in contrast to the benchmark, reemployment wages always fall with duration.

Proposition 3.2 The value of unemployment $U_{\tau}$ and reemployment wages $w_{\tau}$ fall with unemployment duration.

What can be said about the duration dynamics of exit rates from unemployment? If $T=2$, it can be shown that exit rates decrease with duration. ${ }^{14}$ However, in the general case, this is more difficult to establish as the two components of the exit rates in the NR economy, $h_{\tau}\left(q_{\tau}\right)=p_{\tau} \nu\left(q_{\tau}\right)$, can move in opposite directions. The first component is related to the sorting mechanism and always declines with unemployment duration if $\lambda_{\ell}<\lambda_{h}$. The second factor also falls if $q_{\tau}$ increases, which requires that the joint value $\Delta_{\tau}$ or, equivalently, ex-post profits decline with duration, according to the zero-profit condition (23). However, the profits from hiring a worker may increase with the length of her unemployment duration. For example, consider the limit case of $y_{\ell}=y_{h}$. Expected productivity $\bar{y}_{\tau}$ remains constant as duration increases, and the joint value $\Delta_{\tau}$ and the profits $\left(1-\frac{e^{-q_{\tau}} q_{\tau}}{1-e^{-q_{\tau}}}\right) \Delta_{\tau}$ increase because of the steady decline in the unemployment value $U_{\tau}$. In this case, the second component of the exit rates, $\nu\left(q_{\tau}\right)$, increases because of a larger firm entry generated by the increase in $\Delta_{\tau}$. Therefore, the duration pattern of the exit rates is ambiguous as the two factors move in opposite directions as duration increases.

\subsection{The Qualitative Effects of Ranking by Duration}

In our model, sorting leads to an endogenous preference for workers with short unemployment spells. The multilateral meeting technology together with their ability to discriminate at the hiring stage permits firms to treat different applicants differently. Against the backdrop of our discussion of the NR economy we now highlight the role of the firms' ranking decision.

First, note that the ranking result is independent of whether firms have the ability to commit to wages contingent on expected productivity or not. If firms can only commit to a single wage contract as in Lang et al. (2005) and Peters (2010), ranking by productivity is an obvious outcome. In our setting, like in Shi (2002) and Shimer (2005a), as contingent wages

\footnotetext{
${ }^{14}$ When $T=2$, the labor market is fully segmented as the short-term unemployed workers are more profitable than their long-term counterparts, i.e. $\Delta_{1}>\Delta_{2}$. As a result, the zero-profit condition implies that $q_{1}<q_{2}$, and, hence, exit rates fall with unemployment duration. Proposition 3.2 states that equilibrium wages $w_{\tau}$ also fall. Notice that this contrasts with the increasing wages over unemployment duration in the benchmark if worker types are sufficiently close in one dimension as stated in Proposition 2.5
} 
reward worker's marginal value, they are compressed enough so that the ex-post profits fall with expected productivity, and, hence, ranking by expected productivity is an optimal decision.

The firm's ability of establishing a hiring order and offering different wages is instrumental in the labor market being non-segmented in equilibrium. By attracting all workers, firms increase the chances to fill their vacancies. Moreover, the ranking of applicants allows firms to further reduce the wage bill for any unemployment duration as they no longer face the standard trade-off between a lower wage and a lower job-filling probability, since it is now attenuated by the presence of applicants with longer unemployment spells. As a result, exit rates fall because of sorting, which lowers the probability of passing the test as unemployment duration increases, and the ranking decision of firms, which makes callback rates fall with duration.

When ranking is not permitted instead, the market is segmented in equilibrium. To better understand this, consider the $T=2$ case. When firms have only wages as an instrument to discriminate among applicants, they find it too costly to attract observationally different workers at the same time. Suppose that a firm targeting only workers of duration $\tau=1$ offered the job also to workers with longer unemployment spells to increase the probability of filling the vacancy. In equilibrium, this positive effect on expected profits would be dominated by two negative effects. First, the firm would have to compensate the $\tau=1$ applicants with higher wages because of the reduction in their job-finding probability. Second, conditional on filling the vacancy, expected profits would be lower because expected productivity declines over unemployment duration as stated in Proposition 2.3. In contrast, all firms find it optimal to attract all types of workers in the benchmark economy because the two negative effects do not occur when firms can discriminate among candidates in the hiring stage.

Notice that the result of ranking by duration is preserved even for arbitrarily small differences across worker types. Put differently, ranking has the potential to significantly amplify the effects of worker differences in either productivity or suitability rates on exit rates. We discuss the magnitudes of the ranking effect in the following section.

\section{Quantitative Exploration}

We next calibrate the model to the U.S. economy to gauge how well the benchmark model captures the data, and to illustrate the quantitative effects of the ranking mechanism. To 
better summarize these effects, we often focus on the values at 3 months of unemployment. ${ }^{15}$ Furthermore, we use the calibrated model to explore how the duration dynamics of callback rates, exit rates and wages are affected by changes in aggregate productivity.

\subsection{Calibration and Results}

For this numerical illustration, we use publicly available data from Current Population Survey (CPS) and targets from the literature. We present the details of our data work in the Online Appendix. We now outline our calibration strategy.

We set a period to be a week despite transition rates in and out of unemployment being estimated at a monthly frequency. The reason for this choice is twofold. First, unemployment duration is reported in weeks by the subjects surveyed in the CPS, and most of the action takes place within the first 15 weeks of unemployment. Second, it alleviates the time aggregation bias of the transition rates as we can construct the model counterparts of actual monthly aggregates. We comment on this issue further below. The weekly discount factor $\beta$ matches a yearly interest rate of $5 \%$. The parameter defining the state of long-term unemployment, $T$, is set equal to 52 weeks. ${ }^{16}$ We normalize the market productivity of the skilled workers to one, $y_{h}=1$.

We then jointly calibrate the parameters $b, k, \delta, \lambda_{h}, \lambda_{\ell}, \mu$, and $y_{\ell}$. Following Hall and Milgrom (2008), we set $71 \%$ of average worker productivity as the target for $b$. Parameter $k$ is calibrated to match the ratio of vacancy costs to the simulated average quarterly wage per hire, which is estimated to be $13 \%$ by Abowd and Kramarz (2003) -the number Hall and Milgrom (2008) use is $14 \%$-.

The remaining parameters are related to labor market transitions. We use targets from the predicted distributions obtained from our data set as described in the Online Appendix. ${ }^{17}$ The target for the job-separation rate $\delta$ is the average monthly transition rate from employ-

\footnotetext{
${ }^{15}$ The reason to choose this specific duration is twofold: it is approximately the average unemployment duration in our sample, and marks a clear change in the slope of the duration distribution of exit rates. Moreover, only approximately $17 \%$ of the observations in our sample correspond to unemployment durations longer than 6 months.

${ }^{16}$ In our dataset $97 \%$ of the transitions from unemployment to employment correspond to spells shorter than one year. Moreover, we find that our results are robust to changes in $T$. For example, an increase (decrease) of $T$ by $50 \%$ changes the fall of the exit rate at duration 3 months, relative to the first week, from $51.68 \%$ in the benchmark calibration to $52.30 \%$ (50.49\%) after recalibrating.

${ }^{17}$ Recall expectations are quite common in the U.S. Since we do not model recall, workers expecting to be rehired by a former employer are not counted as unemployed in the calibration targets we compute from our predicted data. See e.g. Pries and Rogerson (2005) and Bils et al. (2011) for a similar approach. Fujita and Moscarini (2012) find that $85 \%$ of workers in temporary layoff are rehired. This significantly affects our estimates of the transition rates.
} 
Table 1: Calibration

\begin{tabular}{|c|c|c|c|}
\hline Parameter & Description & Value & Target \\
\hline \multicolumn{4}{|c|}{ Exogenously Set Parameters } \\
\hline $\bar{\beta}$ & Discount factor & 0.999 & Annual interest rate of $5 \%$ \\
\hline$T$ & LTU-defining duration & 52 & - \\
\hline$y_{h}$ & Productivity of skilled & 1.0 & (Normalization) \\
\hline \multicolumn{4}{|c|}{ Jointly Calibrated Parameters } \\
\hline$\delta$ & Job-separation rate & 0.0033 & Predicted monthly job-separation rate \\
\hline$k$ & Vacancy cost & 0.7071 & $13 \%$ avg. quarterly wage per hire \\
\hline$b$ & Home productivity & 0.6968 & $71 \%$ of avg. productivity \\
\hline$\lambda_{h}$ & Skilled suitability prob. & 0.3195 & Avg. duration prior to $\mathrm{E}$ within next month \\
\hline$\lambda_{\ell}$ & Unskilled suitability prob. & 0.0832 & \multirow{3}{*}{$\begin{array}{l}\text { St. dev., skewness } \\
\text { and kurtosis of } \\
\text { monthly exit rates }\end{array}$} \\
\hline$\mu$ & Share of skilled & 0.3439 & \\
\hline$y_{\ell}$ & Productivity of unskilled & 0.9712 & \\
\hline
\end{tabular}

ment $(E)$ to unemployment $(U)$. The predicted $E U$ transition rate has a period average of $0.009 .{ }^{18}$

Petrongolo and Pissarides (2001) find that the simple version of the urn-ball matching technology implies too low an unemployment duration for a given ratio of vacancies to unemployment. To improve the fit to the data they suggest to add an additional friction in the form of match-specific suitability. This is indeed the role played by $\lambda_{h}$ in our setting (whereas $\frac{\lambda_{\ell}}{\lambda_{h}}$ accounts for the relative suitability of the unskilled). Therefore, we set $\lambda_{h}$ to match an average unemployment duration of 12.57 weeks. ${ }^{19}$

The remaining parameters, $\lambda_{\ell}, \mu$, and $y_{\ell}$, are related to the unobserved heterogeneity across workers. Because differences in types translate into differences in job-finding rates, our strategy is to make the model replicate the actual duration distribution of monthly exit rates. Specifically, we target the standard deviation (0.0801), skewness (0.7725), and kurtosis (2.3267) of the distribution of the predicted monthly exit rates.

Time aggregation bias in the transition rates among employment states has been found to be quantitatively important, particularly when estimating $E U$ transition rates. The standard correction for this bias assumes a duration-independent exit rate, see Shimer (2005b). Obviously, this assumption fails to hold in our setting. Instead of correcting for it in the data, we simulate data from the model and aggregate appropriately to obtain the model counterparts of the monthly numbers from the data. For example, for the monthly job-

\footnotetext{
${ }^{18}$ This estimate is much lower than the standard one, reported e.g. in Shimer (2005b) for the 1951-2003 period. Yet, it is close to the numbers found by Fujita and Moscarini (2012), also for the period 1994-2012 and conditioning on permanent separations, and close to the estimate in Pries and Rogerson (2005).

${ }^{19}$ To be precise, average duration is computed as the average length of unemployment spells conditional on finding a job within the next month both for actual and simulated data.
} 
separation rates, we compute, out of the total mass of workers who are employed at the beginning of a given period, how many have become unemployed four periods later. We do take into account that displaced workers can find new jobs in each of the interim periods, but we do not consider further rounds in and out of unemployment as their occurrence is negligible.

Table 1 summarizes our procedure and estimates. All the targets are very accurately matched. One out of three workers in our economy is skilled, and they account for about $11 \%$ of the unemployed. The skilled are about four times more likely to be suitable, and almost $3 \%$ more productive when employed. ${ }^{20}$ We can compare our model outcomes to other available data moments not targeted in the calibration. First, the model steady state unemployment rate is 3.79 , slightly below its data counterpart of 4.18 . Second, the number of the tested unemployed per vacancy is 5.17 in the model, close to the 6.33 documented by Barron et al. (1985) for the U.S. 1980 EOPP survey, but far away from the 12 reported by van Ours and Ridder (1992) using Dutch 1987 data.

We now turn to the duration profiles of exit rates, callback rates, and wages. Figure (a) depicts normalized simulated data of the monthly exit rates from our calibrated model together with the actual values. The model matches the actual duration function of the exit rates from unemployment remarkably well. The monthly job-finding rate after 13 weeks of unemployment, roughly the average unemployment duration, is $51.68 \%$ of the rate at the first week (vs. $50 \%$ in the data). As in the actual data, the simulated duration function shows a severe decline over the first 3 months and flattens out from then on. Furthermore, we also closely match the level of the non-normalized exit rates not targeted in the calibration. The simulated monthly job-finding probability at the first week of unemployment is 0.43 , whereas it is 0.44 in the data.

Moreover, our calibrated model delivers a distribution of callback rates. As shown in Figure 2, these rates strongly fall across duration. Specifically, callback rates fall by $24 \%$ from one month of unemployment to six months. The field experiments conducted in OberholzerGee (2008) for Switzerland, Kroft et al. (2013) for the U.S. and Eriksson and Rooth (2014)

\footnotetext{
${ }^{20}$ Our interpretation of the small difference in productivities together with the large difference in suitability rates is as follows. The suitability friction has a direct effect on the duration distribution of exit rates. In contrast, productivity differences only affect them indirectly through its effects on vacancy creation, and such effects are attenuated because of the ranking decision of firms. That is, regardless of how low the expected productivity is, the exit rate of a suitable candidate with a 10-week unemployment spell is primarily reduced by the presence of other applicants with shorter durations who are ranked higher. In contrast, in the NR economy, productivity has a much stronger effect on vacancy creation for all durations and thus productivity differences need to be larger to match a given duration profile of exit rates. Specifically, when the NR economy is calibrated to the same set of targets (as reported in Appendix 6.4), productivity differences are much larger, while the suitability rates are marginally different from the ones in the baseline calibration.
} 


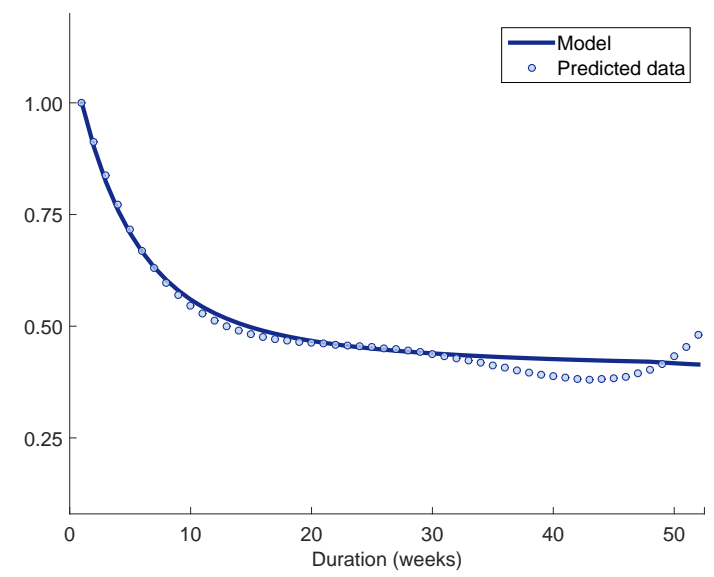

(a) Monthly Exit Rates

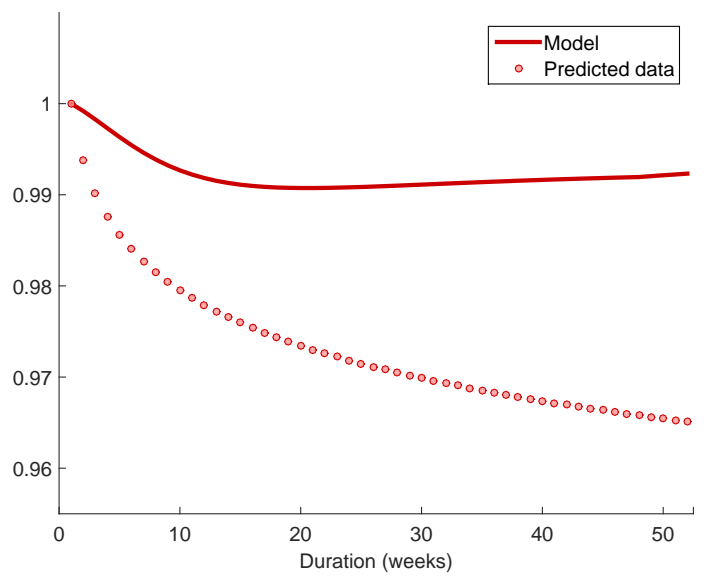

(b) Reemployment Wages

Figure 1: Distributions over Unemployment Duration: Model and Data.

Note: Exit rates from unemployment are the transition rates from unemployment to employment within the following month. Wages are the expected wage conditional on being employed after four weeks. All values are normalized by the value at the first week.

for Sweden also show a steep decline of callback rates along duration. In particular, in Kroft et al. (2013) fictitious job-seekers of different unemployment duration each submit a single application and wait for an interview call for up to 6 weeks, although most calls arrive within the first two weeks. They find that their estimated callback rates fall by $20 \%$ from one month of unemployment to six months.

Next, we consider reemployment wages. Recall that we do not use any target related to wages in our calibration. Figure 1(b) displays the normalized simulated wages together with the normalized predicted wages estimated from CPS data. To be consistent with the data counterpart, simulated wages for any duration $\tau$ are computed as the expected wage conditional on being employed after 4 weeks. While we show the wages on a magnified scale for better visibility, the model distribution of wages over unemployment duration is very close to the actual one. Indeed, model wages are compressed slightly more than what we observe in the data. They fall by $0.8 \%$ after three months of unemployment (vs. $2.3 \%$ in the data) and very slightly increase towards the end. Another way to compare the two wage series is to compute the duration elasticity of the simulated wages by applying the regression procedure that we used for the actual data. We obtain that the data and simulated duration elasticities are -0.0090 and -0.0032 , respectively.

Why is our model able to generate the diverging pattern of exit rates and wages present in the data? Notice that workers are heterogenous along two dimensions, which both affect wages and exit rates. The productivity difference, $y_{h}-y_{\ell}$, is fairly small in our calibration 
and thus expected productivity and wages do not fall much along duration. In contrast, the large difference in the suitability parameters $\lambda_{h}$ and $\lambda_{\ell}$ allows for a large variation of the probability of being suitable, $p_{\tau}$, across durations. This makes the fall in exit rates strong. As we argue below, the ranking component also substantially contributes to explaining the different slopes of exit rates and wages along duration.

Decomposing the Exit Rate Dynamics. We now decompose the exit rates from our calibrated economy into its three components determined in expression (6), i.e. the callback rate $\left(e^{-\sum_{\tau^{\prime}<\tau} q_{\tau^{\prime}}}\right)$, the probability of passing the suitability test $\left(p_{\tau}\right)$, and the pure coordination friction for duration- $\tau$ workers $\left(\left(1-e^{-q_{\tau}}\right) / q_{\tau}\right)$. Figure 2 plots the job-finding rate as well as its components, all normalized by the respective first value. As the components cannot be individually time-aggregated we report weekly values. Both the callback rates,

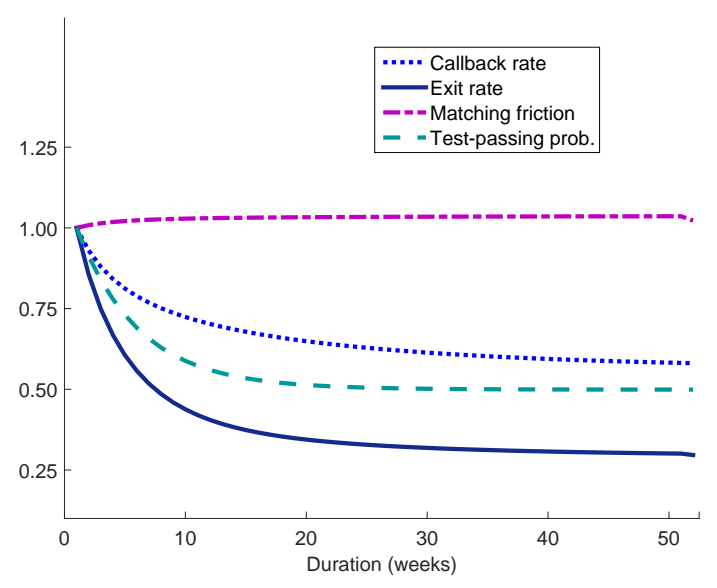

Figure 2: Components of Weekly Exit Rates

Notes: All values are determined on a weekly basis and normalized by the value at the first week.

which capture the ranking decision, and the probability of being suitable first rapidly decline and then flatten out. The latter declines fast initially because of the large differences in suitability rates leading to a strong sorting effect that becomes less pronounced as the pool of unemployed more and more consists only of unskilled applicants. Further, due to sorting and hiring, the pool of unemployed, and thus the ratio $q_{\tau}$, becomes smaller with duration. This implies that a worker of low duration has relatively many competitors from the next lower duration, whereas this is not as pronounced for workers with long spells. Thus, the callback rate initially declines fast and then becomes flatter with duration. Finally, as $q_{\tau}$ decreases the coordination friction becomes less severe and therefore slightly increases with duration. Unlike the first two components, the pure coordination friction does not contribute much to 
the duration dynamics in quantitative terms. ${ }^{21}$

\subsection{The Quantitative Effects of Ranking by Duration}

To provide further insights on the quantitative effects of ranking, Figure 3(a) plots the exit rate of the benchmark model with $(h)$ and without $(\hat{h})$ the callback rate component as well as the exit rates of the NR economy $\left(h^{N R}\right)$ using the same calibrated parameters. Going from the overall exit rate $h$ to the counterfactual rate $\hat{h}$, we see that without the ranking effect the duration profile becomes much flatter. This difference is due to the amplifying effect of ranking on the fall of the exit rate. Next, the move from $\hat{h}$ to $h^{N R}$ captures the additional general equilibrium effects of ruling out ranking. While the slope of the duration profile stays similar to the one of $\hat{h}$, there is a downward shift of the whole distribution in addition. As a result, without ranking workers of low duration have a lower exit rate, whereas it is the opposite for workers with high duration. In the benchmark economy, workers with short unemployment spells face more job opportunities than in the NR economy because of a larger entry of firms due to higher expected profits and being ranked ahead. In contrast, applicants with longer unemployment spells are discriminated against in the benchmark, which is not the case in the NR economy. Our calibration suggests that the difference between the two environments regarding the decline of the exit rates is quantitatively significant. The fall in the monthly exit rate after 3 months relative to the first week is $48 \%$ in the benchmark -which is closely matching the fall in the data-, and only $37 \%$ in the NR economy. ${ }^{22}$

We can also show the effects of ranking on wages. Similar to the above comparison we first compute counterfactual wages by omitting the summation term from expression (14). As explained above, this summation term is due to the ability of the firm to rank applicants and represents the expected value of the next best alternative. To capture the general equilibrium effect we compare to the wages of the NR economy, again using the parameters of the calibrated benchmark model. Figure $3(\mathrm{~b})$ shows the wages for the benchmark $(w)$, the counterfactual wages without the ranking component $(\hat{w})$, and the NR wages $\left(w^{N R}\right)$, which fall by $1.3 \%$ after three months of unemployment.

Wages of low durations are increased more than wages for high duration when we remove

\footnotetext{
${ }^{21}$ In terms of levels, only the sorting factor is significantly below one at the first week and thus is the dominating component for determining the level of the job-finding rate at the first week. Recall that the callback rate at the first week is one by construction.

${ }^{22}$ While the distributions of the exit rates strongly differ across economies, the average monthly job-finding rates and implied unemployment rates are quite similar. They are $26.4 \%$ and $3.8 \%$ for the benchmark economy and $26.6 \%$ and $3.6 \%$ for the NR economy, respectively. Further, the vacancy rates are $0.72 \%$ for the benchmark and $0.75 \%$ for the NR economy, respectively.
} 


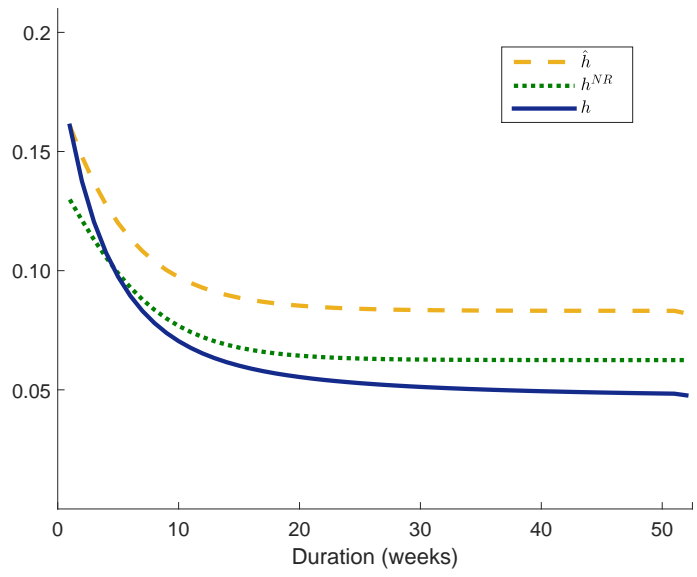

(a) Exit Rates

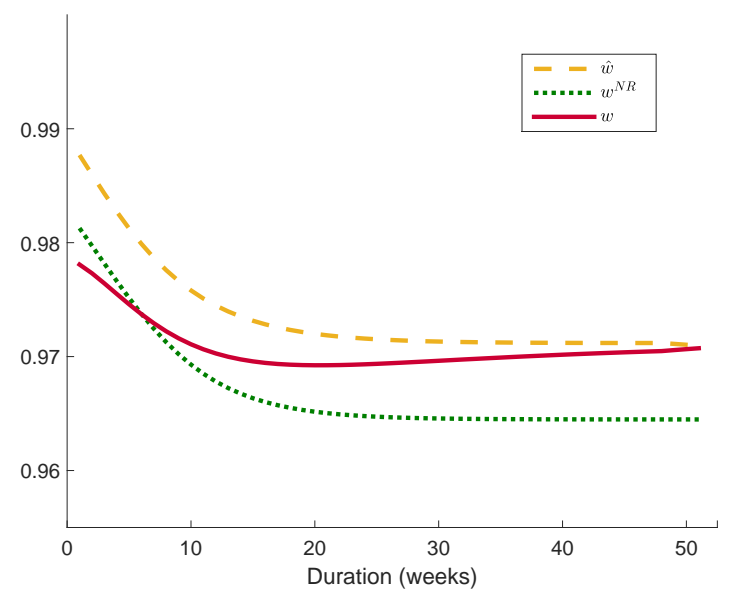

(b) Wages

Figure 3: The Effects of Ranking

Note: Exit rates and wages are determined on a weekly basis and reported as non-normalized values. Symbols $h$ and $w$ refer to the equilibrium exit rates and wages in the benchmark economy, whereas $\hat{h}$ and $\hat{w}$ denote the same rates and wages without the ranking factor. Symbols $h^{N R}$ and $w^{N R}$ denote the equilibrium exit rates and wages in the NR economy.

the ranking component of wages, i.e. when moving from $w$ to $\hat{w}$. This is due to the fact that the expected value of the next best alternative is higher for applicants of low duration. If in addition general equilibrium effects are taken into account, wages $w^{N R}$ still show a steeper decline, and are shifted downwards so that only workers with short spells get a higher wage in the case of no ranking. Wages across duration are therefore more compressed in the presence of ranking.

If we instead recalibrate the NR economy using the same targets, exit rates will match closely the targeted empirical exit rates, but now wages will decline much more strongly than in the data because the difference in the productivity values across types is now much larger. See the Online Appendix for details. Thus, the ranking element helps to capture the duration profiles of both exit rates and wages in the data.

As an anonymous referee points out, the sizable effect of ranking may depend on the stylized way we model the testing technology. In particular, if firms also received some signal on productivity when screening applicants, the information conveyed by unemployment duration might play a smaller role and the quantitative effects of ranking might be smaller. In the Online Appendix we investigate the quantitative effects of such a more general testing technology and find only minor differences.

The previous analysis has decomposed the duration dynamics of exit rates and wages into its main driving factors, namely ranking and sorting. Recall that ranking is an endogenous 
response to sorting in our model and therefore cannot be considered as an independent factor. In particular, the relationship between ranking and sorting is very non-linear. When there are no differences in suitability rates, unemployment duration is not informative, and hence firms have no reason to rank candidates. However, even if there is an arbitrarily small difference in suitability rates, firms will rank, thereby largely affecting callback rates. To give an example, in our calibrated benchmark, the weekly rate of being suitable declines by $45 \%$ after 3 months, whereas callback rates fall by $31 \%$. Now, if we decrease $\lambda_{h}$ to a value of just $5 \%$ above $\lambda_{\ell}$, the fall in the suitability factor reduces to less than a tenth of a percent, whereas callback rates still decline by $27 \%$. Likewise, the wage fall is reduced from $1 \%$ to approximately $0 \%$. Thus, even a small amount of unobserved heterogeneity can lead to a large effect on callback rates.

\section{Discussion and Conclusion}

This article analyzes the effects of firm's recruiting decisions in a labor market in which information on worker type is symmetric and incomplete and firms test applicants. Our composite mechanism combines sorting and ranking, and there exists a single labor market in equilibrium. The model rationalizes the joint declining pattern of callback rates for an interview, exit rates from unemployment and reemployment wages.

A natural question is how sensitive the main results are to the information structure of the model conditional on information being symmetrically held. Although these assumptions are made for tractability, we conjecture that if either complete worker histories were observable or the continuation value depended on the worker's search, ranking by expected productivity would still take place in equilibrium because of the two incentives firms have to attract many applicants, namely to increase the job-filling probability and to reduce wages because the marginal value of a worker is reduced by the presence of other applicants. However, if the whole labor history were observable, expected productivity would be inferred from the whole history of the worker instead of from the current spell and the single-market equilibrium feature would be preserved. We conjecture that, if workers did learn from their job-search experience, e.g. from receiving test calls or from the expected queue length associated to their individual application, multiple labor submarkets would be active in equilibrium and ranking by unemployment duration would prevail in each submarket.

Furthermore, by reducing the whole learning process to a test, probationary periods are ruled out in our model. Our intuition is that firms would continue to rank applicants by expected productivity if probation and more complex wage schemes were allowed. This is 
because in any case firms would prefer to fill the vacancy with candidates of higher expected productivity. If instead wages could not be re-adjusted when new information is acquired, then modeling worker's type as an experience good would make dismissals informative, which would get us back to the previous discussion about the importance of the whole labor history of workers. In contrast, in our setting worker's productivity is an inspection good, thereby limiting the information to the unemployment spell.

Our paper has focused on the positive analysis of equilibrium. It turns out that unlike in the static settings of Shi (2002) and Shimer (2005a) the decentralized allocation is not constrained efficient due to an intertemporal information externality. We investigate and discuss this issue in the Online Appendix.

Finally, although this paper has focused on the steady-state equilibrium, notice that the information conveyed by the length of joblessness spells varies over the cycle. In tight labor markets, with a large number of vacancies per job-seeker, unemployment duration is more informative about the expected skills of the applicants than in slack markets. Although our comparative static analysis in the Online Appendix suggests that the ranking by duration dominates the sorting effects, a more comprehensive business cycle study is needed, which we leave for future research.

\section{References}

AbBring, J. and van Ours, J. (1994). Sequential or non-sequential employers' search? Economics Letters, 44 (3), 323-328.

Abowd, J. and Kramarz, F. (2003). The costs of hiring and separations. Labour Economics, 10 (5), 499-530.

Barron, J. M., Bishop, J. and Dunkelberg, W. C. (1985). Employer search: The interviewing and hiring of new employees. The Review of Economics and Statistics, 67 (1), 43-52.

Bils, M., Chang, Y. and Kim, S.-B. (2011). Worker heterogeneity and endogenous separations in a matching model of unemployment fluctuations. American Economic Journal: Macroeconomics, pp. 128-154.

Blanchard, O. J. and Diamond, P. (1994). Ranking, unemployment duration, and wages. The Review of Economic Studies, 61 (3), 417-434. 
Calvo-Armengol, A. and Jackson, M. O. (2004). The effects of social networks on employment and inequality. The American Economic Review, 94 (3), 426-454.

Coles, M. G. and Smith, E. (1998). Marketplaces and matching. International Economic Review, pp. 239-254.

Doppelt, R. (2015). The hazards of unemployment. mimeo.

Eriksson, S. and Rooth, D.-O. (2014). Do employers use unemployment as a sorting criterion when hiring? evidence from a field experiment. The American Economic Review, 104 (3), 1014-1039.

Farber, H. S., Silverman, D. and Von Wachter, T. M. (2017). Factors determining callbacks to job applications by the unemployed: An audit study. RSF.

Flemming, J. (2015). Skill accumulation in the market and at home. mimeo.

Fujita, S. and Moscarini, G. (2012). Recall and unemployment. Unpublished Manuscript, Yale University.

Gonzalez, F. and Shi, S. (2010). An equilibrium theory of learning, search, and wages. Econometrica, 78 (2), 509-537.

Hall, R. and Milgrom, P. (2008). The limited influence of unemployment on the wage bargain. The American Economic Review, 98 (4), 1653-1674.

Jarosch, G. and Pilossoph, L. (2015). Statistical discrimination and duration dependence in the job finding rate. mimeo.

Kroft, K., Lange, F. and Notowidigdo, M. J. (2013). Duration dependence and labor market conditions: Evidence from a field experiment. The Quarterly Journal of Economics, 128 (3), 1123-1167.

Lang, K., Manove, M. and Dickens, W. T. (2005). Racial discrimination in labor markets with posted wage offers. American Economic Review, pp. 1327-1340.

LOCKWOOD (1991). Information externalities in the labour market and the duration of unemployment. The Review of Economic Studies, 58 (4), 733-753.

Menzio, G. and Shi, S. (2010). Directed search on the job, heterogeneity, and aggregate fluctuations. The American Economic Review, pp. 327-332. 
Moen, E. (1999). Education, ranking, and competition for jobs. Journal of Labor Economics, 17 (4), 694-723.

Moen, E. R. (1997). Competitive search equilibrium. Journal of Political Economy, 105 (2), $385-411$.

Oberholzer-Gee, F. (2008). Nonemployment Stigma as Rational Herding: A Field Experiment. Journal of Economic Behavior and Organization, 65 (1), 30-40.

Peters, M. (1991). Ex ante price offers in matching games non-steady states. Econometrica, $59,1425-1454$.

- (2010). Noncontractible heterogeneity in directed search. Econometrica, 78 (4), 11731200.

Petrongolo, B. and Pissarides, C. (2001). Looking into the black box: A survey of the matching function. Journal of Economic Literature, 39 (2), 390-431.

Pissarides, C. A. (1992). Loss of skill during unemployment and the persistence of employment shocks. The Quarterly Journal of Economics, 107 (4), 1371-1391.

Pries, M. and Rogerson, R. (2005). Hiring policies, labor market institutions, and labor market flows. Journal of Political Economy, 113 (4), 811-839.

SHI, S. (2002). A directed search model of inequality with heterogeneous skills and skillbiased technology. The Review of Economic Studies, 69 (2), 467-491.

Shimer, R. (2005a). The assignment of workers to jobs in an economy with coordination frictions. Journal of Political Economy, 113 (5), 996-1025.

- (2005b). The cyclical behavior of equilibrium unemployment and vacancies. American Economic Review, 95 (1), 25-49.

van Ommeren, J. and Russo, G. (2009). Firm recruitment behaviour: Sequential or non-sequential search? IZA Discussion Paper No. 4008.

VAn Ours, J. and Ridder, G. (1992). Vacancies and the Recruitment of New Employees. Journal of Labor Economics, 10 (2), 138-155. 


\section{Appendix}

\subsection{Proofs}

\section{Proof of Proposition 2.1}

We first show that there exists a solution to the firm's problem (13). After some manipulations and substituting out the wages from the complementary slackness conditions (8), the firm's problem can be rewritten as

$$
\max _{q^{T}} \sum_{\tau=1}^{T}\left(\eta_{\tau}\left(q^{\tau}\right) \Delta_{\tau}-q_{\tau} \frac{U_{\tau}-b-\beta U_{\tau+1}}{p_{\tau}}\right)
$$

where $\Delta_{\tau}=\frac{\bar{y}_{\tau}+\beta \delta U_{1}}{1-\beta(1-\delta)}-b-\beta U_{\tau+1}$. If a sufficiently low wage $w_{\tau}$ for some $\tau$ is offered, then $q_{\tau}=0$ and the firm derives no profits from type $\tau$ applicants.

Notice that the profit function is continuous in $q^{T}$. The set of plausible vectors $q^{T}$ can be restricted to a compact set since they must be non-negative and the complementary slackness conditions (8) puts an upper bound for any duration $\tau$. Therefore, the Weierstrass Theorem ensures the existence of a solution.

Second, we prove by contradiction that if there exists a symmetric equilibrium, then $q_{\tau}>0$ for all $\tau$. Suppose that there exists at least one duration group of workers such that its associated queue is 0 . Let us denote by $\tau_{0}$ the first duration for which the queue length is 0 . To be consistent with the guess that profitability falls with unemployment duration, which is confirmed in Proposition 2.3, all queues associated with longer durations must also be 0 . Then, the unemployment value of workers with unemployment duration greater than or equal to $\tau_{0}$ must be $b /(1-\beta)$ as they will remain unemployed forever. Let $\omega$ be the profitmaximizing contract. Given that $y_{\ell}>b$, there exists an arbitrarily small, but positive $\epsilon$ such that $b+\epsilon<\bar{y}_{\tau_{0}}$. Consider now the alternative contract $\omega^{\prime}$ that stipulates the same wages as $\omega$, but offers type $\tau_{0}$ workers a wage $b+\epsilon$. Because of the ranking strategies, workers of duration $\tau_{0}$ do not crowd out the candidates with higher expected productivities, and imply expected positive profits for the firm. Because the alternative contract $\omega^{\prime}$ delivers strictly higher profits than $\omega$, this cannot be profit-maximizing. Therefore, $q_{\tau}>0$ for all $\tau$.

Finally, we show that if $\Delta_{\tau}$ falls with $\tau$, then the solution of the firm's problem is unique, and is characterized by the first order conditions. 
The Hessian of function $F$ is $D^{2} F=\left(h_{i j}\right)_{i, j}$, where for any given pair $(i, j)$, with $i \leq j$,

$$
h_{i j} \equiv \sum_{\tau \geq j} \frac{\partial^{2} \eta_{\tau}\left(q^{\tau}\right)}{\partial q_{i} \partial q_{j}} \Delta_{\tau}=-\sum_{s=j}^{T-1} e^{-\sum_{\tau \leq s} q_{\tau}}\left(\Delta_{s}-\Delta_{s+1}\right)-e^{-\sum_{\tau \leq T} q_{\tau}} \Delta_{T}
$$

As $\Delta_{\tau}$ declines with $\tau$, all the coefficients of the Hessian matrix are negative, $h_{i j}<0$. To show that the Hessian is negative definite, we prove that the leading principal minors of the Hessian alternate signs. Notice that $h_{i j}$ does not depend on $i$. Thus, the Hessian has a very particular form as $h_{i j}=h_{i^{\prime} j}$ for all $i, i^{\prime} \leq j$ and, obviously, $h_{i j}=h_{i j^{\prime}}$ for all $j, j^{\prime} \leq i$. Let $z_{j} \equiv h_{j j}$ and $\left|H_{j}\right|$ denote the leading principal minor of the Hessian with the first $j$ rows and columns.

$$
\left|H_{j}\right|=\left|\begin{array}{ccccc}
z_{1} & z_{2} & z_{3} & \ldots & z_{j} \\
z_{2} & z_{2} & z_{3} & \ldots & z_{j} \\
z_{3} & z_{3} & z_{3} & \ldots & z_{j} \\
\ldots & \ldots & \ldots & \ldots & \ldots \\
z_{j} & z_{j} & z_{j} & \ldots & z_{j}
\end{array}\right|=\left|\begin{array}{ccccc}
z_{1}-z_{2} & 0 & 0 & \ldots & 0 \\
z_{2}-z_{3} & z_{2}-z_{3} & 0 & \ldots & 0 \\
z_{3}-z_{4} & z_{3}-z_{4} & z_{3}-z_{4} & \ldots & 0 \\
\ldots & \ldots & \ldots & \ldots & \ldots \\
z_{j} & z_{j} & z_{j} & \ldots & z_{j}
\end{array}\right|,
$$

where the second determinant obtains from subtracting each row of $\left|H_{j}\right|$ to its previous one. Then,

$$
\begin{gathered}
\left|H_{j}\right|=z_{j} \prod_{s<j}\left(z_{s}-z_{s+1}\right)=z_{j} \prod_{s<j}\left(-e^{-\sum_{\tau \leq s} q_{\tau}}\left(\Delta_{s}-\Delta_{s+1}\right)\right)= \\
=(-1)^{j-1} z_{j} \prod_{s<j}\left(e^{-\sum_{\tau \leq s} q_{\tau}}\left(\Delta_{s}-\Delta_{s+1}\right)\right)
\end{gathered}
$$

The sign of the expression is positive if $j$ is even and negative otherwise. Therefore, the Hessian is negative definite and the FOC are also sufficient. Furthermore, since this is the case at any point, the objective function is strictly concave and there is a unique global maximum. \|

\section{Proof of Proposition 2.5.}

Consider first the case of small differences in the suitability rate, $\lambda_{h}=\lambda_{\ell}+\epsilon$, with $\epsilon>0$ arbitrarily small. After some simple simplifications, we can write the difference in expected 
productivities as

$$
\begin{aligned}
\bar{y}_{T-1}-\bar{y}_{T} \leq & \bar{y}_{T-1}\left(1-\left(1+\epsilon \frac{\frac{\nu_{T-1}\left(q^{T-1}\right)}{1-\lambda_{h} \nu_{T-1}\left(q^{T-1}\right)}}{y_{h} \lambda_{h} u_{h}(T-1)+y_{\ell} \lambda_{\ell} u_{\ell}(T-1)}\right) \times\right. \\
& \left.\frac{\lambda_{h} u_{h}(T-1)+\lambda_{\ell} u_{\ell}(T-1)}{\lambda_{h} u_{h}(T-1)+\lambda_{\ell} u_{\ell}(T-1)\left(1+\frac{\epsilon \nu_{T-1}\left(q^{T-1}\right)}{1-\lambda_{h} \nu_{T-1}\left(q^{T-1}\right)}\right)}\right)
\end{aligned}
$$

Notice that the right hand side vanishes as $\epsilon$ goes to 0 . Therefore, the left hand side of the last inequality of the counterpart of expression (15) for durations $T-1$ and $T$ is arbitrarily close to 0 , whereas the right hand side is strictly positive, which implies $w_{T-1}<w_{T}$.

The case with arbitrarily small differences in productivity is obvious because the expected productivity $\bar{y}_{\tau}$ is a convex combination of $y_{\ell}$ and $y_{h}$, and, hence, $\bar{y}_{T-1}-\bar{y}_{T}<y_{h}-y_{\ell} . \|$

\section{Proof of Proposition 3.1}

Consider the case in which all recruiting firms target a single duration by posting contract $\omega_{\tau}$, which has all its components equal to 0 except the wage $w_{\tau}$. Let a submarket be defined by the pair $\left(q_{\tau}, \omega_{\tau}\right)$ that is the maximizer of the firm problem (21). Given $u$ and $\left(U_{\tau}\right)_{\tau}$, such a solution is pinned down by equations (22) and (23), which correspond to the first order condition and the zero-profit condition, respectively. We define $Q\left(\omega_{\tau}\right)=q_{\tau}$ and $\rho_{\tau}\left(\omega_{\tau}^{\prime}\right)=\mathcal{I}_{\tau}\left(\tau^{\prime}\right)$, where $\mathcal{I}_{\tau}\left(\tau^{\prime}\right)$ is an indicator function that values 1 if $\tau=\tau^{\prime}$ and 0 otherwise. Furthermore, for any other $\omega \in\left[0, y_{h}\right]^{T}, Q(\omega)$ is pinned down by the maximum queue length that makes workers of all durations indifferent to the equilibrium contract to which they apply to. It is easy to show that it satisfies all the remaining equilibrium conditions.

Now, before showing the existence of the fully segmented equilibrium, we prove that there cannot be an equilibrium with a single labor market. If there were a pooling equilibrium, then all workers would face the same expected queue length. Proposition 2.3 states that expected productivity falls with unemployment duration. Therefore, $\Delta_{T-1}>\Delta_{T}$, and the zero-profit condition (23) implies that $q_{T-1}<q_{T}$. That is, workers with unemployment duration $T-1$ and $T$ must search in different submarkets in equilibrium.

We next show the existence of a fully segmented equilibrium, which resembles the proof of Proposition 2.2. Let $f: K \rightarrow K$, where $K \equiv[0,1]^{2 \times T} \times\left[\frac{b}{1-\beta}, \frac{y_{h}}{1-\beta}\right]^{T}$ is a compact set. We define $f$ as the composite correspondence $f \equiv \phi \circ \psi$, where $\phi$ and $\psi$ are defined as follows. First, let $z \equiv\left(u,\left(U_{\tau}^{\prime}\right)_{\tau}\right)$ and $\psi(z)$ be defined as the set of elements $\left\{q_{\tau}, w_{\tau}, U_{\tau}\right\}_{\tau}$ that satisfy the zero-profit conditions (23), solve the firms' profit maximization program (21) and $U_{\tau}$ is obtained as a new iteration using equation (17). Second, let $\phi$ be a function defined as $\phi\left(\omega, q^{T},\left(U_{\tau}\right)_{\tau}\right) \equiv\left(\tilde{u},\left(\tilde{U}_{\tau}\right)_{\tau}\right)$, where $\tilde{u}$ is uniquely determined by the equilibrium recursivity 
condition (18), and $\tilde{U}_{\tau}=U_{\tau}$ for all $\tau$. Notice that the equilibrium allocation can be identified with the solution of a fixed point of correspondence $f$. We are to show that $f$ is a continuous function, and, then, Brouwer's Fixed Point Theorem applies to ensure the existence of a fixed point of $f$.

To show that $f$ is a continuous function, it suffices to show that $\psi(z)$ is singleton and continuous for every $z \in K$ as its other component is obviously a continuous function. Notice that the objective function of program (21), after replacing wages, is strictly concave in $q$. Therefore $\psi$ is a function. The Maximum Theorem ensures that $\psi$ is continuous in $z \in K$. Therefore, the composite function is also a continuous function. $\|$

\section{Proof of Proposition 3.2.}

We first show that the unemployment value falls with duration. The proof is by backwards induction. Recall that the value of unemployment can be written as

$$
U_{\tau}=h_{\tau}\left(q_{\tau}\right) \gamma\left(q_{\tau}\right) \Delta_{\tau}+b+\beta U_{t+1}=p_{\tau} e^{-q_{\tau}} \Delta_{\tau}+b+\beta U_{t+1}
$$

First, we show that $U_{T}<U_{T-1}$.

$$
U_{T}<U_{T-1} \Leftrightarrow p_{T} e^{-q_{T}} \Delta_{T}<p_{T-1} e^{-q_{T-1}} \gamma\left(q_{T-1}\right) \Delta_{T-1}
$$

Notice that $\Delta_{T} \leq \Delta_{T-1}$ and $p_{T}<p_{T-1}$ if $\lambda_{\ell}<\lambda_{h}$. Then, the zero-profit condition (23) implies $q_{T-1} \leq q_{T}$. Therefore, $U_{T}<U_{T-1}$.

Second, we assume that $U_{t+1}<U_{t}$ for $\tau \leq t \leq T-1$, and show that $U_{\tau}<U_{\tau-1}$. Let $\underline{m} \equiv \min \left\{p_{\tau-1} e^{-q_{\tau-1}}, p_{\tau} e^{-q_{\tau}}\right\}$ and $\bar{m} \equiv \max \left\{p_{\tau-1} e^{-q_{\tau-1}}, p_{\tau} e^{-q_{\tau}}\right\}$

$$
\begin{aligned}
U_{\tau-1}-U_{\tau}= & p_{\tau-1} e^{-q_{\tau-1}} \frac{\bar{y}_{\tau-1}+\beta \delta U_{1}}{1-\beta(1-\delta)}-p_{\tau} e^{-q_{\tau}} \frac{\bar{y}_{\tau}+\beta \delta U_{1}}{1-\beta(1-\delta)}+ \\
& +\beta U_{\tau}\left(1-p_{\tau-1} e^{-q_{\tau-1}}\right)-\beta U_{\tau+1}\left(1-p_{\tau} e^{-q_{\tau}}\right)+ \\
\geq & \frac{m}{1-\beta(1-\delta)}+ \\
& +(1-\bar{y}) \beta\left(U_{\tau-1}-\bar{y}_{\tau+1}\right)>0
\end{aligned}
$$

where the last inequality stems from the induction assumption and productivity difference if any.

Now, we turn to prove that wages always fall with unemployment duration. Consider first the case in which the joint value $\Delta_{\tau}$ also falls. Then, the expected queue length $q_{\tau}$ 
must increase for the zero-profit condition (23) to hold in equilibrium. As all the terms in the equilibrium wage equation (22) fall, so do wages. Consider now the case in which $\Delta_{\tau}$ increases with unemployment duration. Then, equation (23) implies that $q_{\tau}$ declines with $\tau$. Now, we can rewrite the zero-profit condition as $k=\eta\left(q_{\tau}\right) \frac{\bar{y}_{\tau}-w_{\tau}}{1-\beta(1-\delta)}$. Since the second factor on the right hand side must increase with $\tau$ because the first factor decreases. Proposition 2.3 establishes that $\bar{y}_{\tau}$ decreases and, hence, so must $w_{\tau}$ for the ex-post profits to increase. $\|$ 